\title{
La Directiva "Whistleblowing": Aspectos clave de su transposición al ordenamiento jurídico español
}

\author{
The Whistleblowing Directive: Key aspects of \\ its transposition into Spanish law
}

\section{José Caro Catalán ${ }^{1}$}

Universidad de Cádiz, Cádiz, España

jose.caro@uca.es

https://orcid.org/0000-0001-9735-155X

\begin{abstract}
RESUMEN: En el presente trabajo se analiza el contenido de Directiva (UE) 2019/1937 del Parlamento Europeo y del Consejo de 23 de octubre de 2019 relativa a la protección de las personas que informen sobre infracciones del Derecho de la Unión y su proceso de transposición al ordenamiento jurídico español. Como punto de partida, se realiza una contextualización del fenómeno del whistleblowing a nivel global. Luego se aborda el contenido esencial de la Directiva, profundizando en los canales de denuncias internos y externos. Y, por último, se abordan los aspectos clave de su transposición al ordenamiento jurídico español. Para llevar a cabo este último epígrafe, el autor se sirve de la consulta pública sobre la transposición de la Directiva planteada por el Ministerio de Justicia el 7 de enero de 2021 así como de algunas de las aportaciones realizadas en el seno de ese proceso por entidades e instituciones interesadas. Por último, el artículo se refiere brevemente al proceso de transposición de la Directiva en otros Estados miembros.

Palabras clave: Canales de denuncias; alertadores; transposición; Derecho de la UE.
\end{abstract}

AвSTRACT: This paper analyses the key aspects of the imminent transposition into Spanish law of Directive (EU) 2019/1937 of the European Parliament and of the Council of 23 October 2019 on the protection of persons who report

1 Investigador Predoctoral FPU-UCA de Derecho Procesal en la Universidad de Cádiz. Miembro del Grupo de Investigación IURISDICTIO-Estudios de Derecho Procesal (SEJ287), financiado por la Junta de Andalucía. 
breaches of Union law. As a starting point, it provides a contextualisation of the phenomenon of whistleblowing at the global level. Then, the essential content of the Directive is addressed, going deeper into the internal and external whistleblowing channels. Finally, the key aspects of its transposition into Spanish law are addressed. To carry out this last section, the author makes use of the public consultation on the transposition of the Directive proposed by the Ministry of Justice on 7 January 2021, as well as some of the contributions made during this process by stakeholders.

KEYWORDs: Reporting channels; whistleblowers; transposition; UE Law.

Contenido: Introducción; 1. Los canales de denuncias: origen, recepción en España y evolución legislativa; 2. La Directiva (UE) 2019/1937 relativa a la protección de las personas que reporten infracciones del Derecho de la Unión; 2.1. Antecedentes; 2.2. Objetivos y ámbito de aplicación; 2.3. Contenido; a) Canales internos de denuncia; b) Canales externos de denuncia y revelación pública de la información; c) Medidas de protección; 3. El proceso de transposición de la Directiva al ordenamiento jurídico español; 3.1. La consulta pública para la transposición de la Directiva de 7 de enero de 2021; a) Ámbito material de aplicación; b) Ámbito personal de aplicación; c) Canales internos de denuncia; d) Canales externos de denuncia; e) Autoridades competentes encargadas de los canales externos de denuncias; f) Sanciones; g) Premios o recompensas; 3.2. Breve referencia al proceso de transposición de la Directiva en otros Estados miembros. Consideraciones finales; Referencias.

\section{INTRODUCCIÓN}

La detección e investigación de las actividades ilícitas que se comenten en el seno de las organizaciones -públicas o privadas- es uno de los principales desafíos a los que se enfrenta la política criminal moderna ${ }^{2}$. Frente a este tipo de criminalidad - denominada corporate crime

2 GARCÍA MORENO, Beatriz. Del whistleblower al alertador: la regulación europea de los canales de denuncia. Valencia: Tirant lo Blanch, 2020, p. 31. 
en el mundo anglosajón ${ }^{3}$ - las medidas de investigación tradicionales se han demostrado claramente ineficaces ${ }^{4}$. Ante este panorama, los Estados tratan de encontrar nuevas -o no tan nuevas- herramientas que les permita perseguir, o incluso prevenir, la comisión de infracciones que se cometen dentro de las organizaciones.

Con este afán, en los últimos años, la protección de las personas denunciantes de irregularidades se está convirtiendo en uno de los elementos centrales de lucha contra este tipo de criminalidad ${ }^{5}$. Se parte de la idea de que las personas que forman parte de una organización están en una posición privilegiada para descubrir las actividades ilícitas o fraudulentas que se desarrollen en su seno. Sin embargo, el miedo a las represalias y el estigma social que recae sobre los denunciantes provocan que en la mayoría de casos las infracciones queden silenciadas. A fin de evitar este tipo de situaciones, los Estados están incorporando a sus ordenamientos garantías adicionales para que los potenciales denunciantes de estas infracciones - principalmente los empleados- se sientan libres y seguros a la hora de denunciar.

El impulso de estas políticas de protección de los denunciantes en los últimos años no tiene su origen -al menos no únicamente- en los Estados, sino que se trata de un fenómeno global fomentado por instituciones internacionales. La protección de los denunciantes ocupa un lugar destacado en la agenda internacional de lucha contra la corrupción

3 ZUÑIGA RODRÍGUEZ, Laura. Corrupción y la categoría de "delito de cuello blanco": cuando los delitos se cometen en contextos normalizados. Revista IUS ET VERITAS, Lima, n. 57, 2018, p. 164.

4 ARMENTA DEU, Teresa. Derivas de la justicia: tutela de los derechos y solución de controversias en tiempos de cambios. Madrid: Marcial Pons, 2021, pp. 178 y ss.

5 RAGUÉS I VALLÈS, Ramón. ¿Es necesario un estatuto para los denunciantes de la corrupción?. Diario La Ley, Madrid, n. 9003, 19 de Junio de 2017, versión digital; SÁEZ LARA, Carmen. La protección de denunciantes: propuesta de regulación para España tras la Directiva Whistleblowing, Valencia: Tirant lo Blanch, 2020, p. 15.

6 SÁEZ LARA, Carmen. La protección de denunciantes: propuesta de regulación para España tras la Directiva Whistleblowing. Valencia: Tirant lo Blanch, 2020, p. 15. 
del G20, del Consejo de Europa y de la Organización para la Cooperación y el Desarrollo Económico (OCDE) ${ }^{7}$.

A nivel de la Unión Europea también se está promoviendo este tipo de políticas. De hecho, en octubre de 2019, el Consejo de la Unión Europea aprobó la Directiva (UE) 2019/1937 del Parlamento Europeo y del Consejo, de 23 de octubre de 2019, relativa a la protección de las personas que informen sobre infracciones del Derecho de la Unión, comúnmente denominada como Directiva "Whistleblowing” (en adelante, la Directiva). Aunque su ámbito de aplicación no solo se refiera a los denunciantes de corrupción, es indudable que la aprobación de esta Directiva ha supuesto un avance significativo en esta materia'. Sin embargo, todavía es pronto para valorar su impacto porque está pendiente de transposición en nuestro derecho interno.

En este trabajo nos proponemos analizar el fenómeno del whistleblowing (1) y, en particular, el contenido de la Directiva (2), con el objetivo final de valorar las opciones que tiene el Estado español a la hora de llevar a cabo su transposición (3). En este último apartado, tendremos muy en cuenta la consulta pública sobre la transposición de la Directiva planteada por el Ministerio de Justicia el 7 de enero de 2021, en la que se deja entrever algunas de las cuestiones clave que se están discutiendo en el proceso de transposición de la norma $(3.1)^{10}$. Además, a fin de ofrecer

7 MECHTENBERG, Lydia., MUEHLHEUSSER, Gerd., ROIDER, Andreas. Whistleblower protection: Theory and experimental evidence. European Economic Review, Ámsterdam, n. 126, 2020, p. 2, BACHMAIER WINTER, Lorena; MARTÍNEZ SANTOS, Antonio El régimen jurídico-procesal del whistleblower. La influencia del Derecho europeo. GÓMEZ COLOMER, Juan Luis, Tratado sobre compliance penal. Valencia: Tirant lo Blanch. 2019, 503-550.

8 "La nueva Directiva "whistleblowing" abre canales seguros de denuncia frente a infracciones del Derecho de la Unión”, Noticias Jurídicas, 27 de noviembre de 2019. Disponible en: <https://noticias.juridicas.com/actualidad/ noticias/14650-la-nueva-directiva-039; whistleblowing039;-abre-canales-seguros-de-denuncia-frente-a-infracciones-del-derecho-de-la-union/>. Acceso en: 23 feb. 2021.

9 GARRÓS FONT, Imma., ROMERA SANTIAGO, Nuria. Hacia una protección efectiva de los denunciantes. Actualidad Administrativa, Madrid, n. 7-8, julio-agosto 2020, p. 2.

10 Consulta pública sobre la transposición de la Directiva planteada por el Ministerio de Justicia el 7 de enero de 2021: Disponible: <https://www.mjusticia. gob.es/es/AreaTematica/ActividadLegislativa/Documents/Consulta\%20Pu- 
una panorámica más completa, nos referiremos brevemente al proceso de transposición de la Directiva en otros Estados miembros (3.2), lo que nos permitirá ofrecer una perspectiva comparada de las cuestiones más relevantes que se están suscitando en su transposición.

En atención a los modestos objetivos formulados en el párrafo anterior, nos planteamos una serie de preguntas a las que trataremos de dar respuesta a lo largo de este trabajo: ¿Sería suficiente con una transposición de mínimos de la Directiva para conseguir una protección efectiva de los denunciantes en España? ¿Debe el legislador español aprovechar la transposición de la Directiva -que solo se refiere a la protección de las personas que denuncian infracciones del Derecho de la Unión- para regular, de forma general e integral, los canales de denuncia? ¿Cuáles son los aspectos clave que pueden ser determinantes para valorar el éxito o el fracaso del proceso de transposición? Y, en su caso, ¿Qué opción sería la más adecuada para cada uno de estos aspectos en el caso de España?

\section{Los CANALES DE DENUNCIAS: ORIGEN, RECEPCIÓN EN ESPAÑA Y EVOLUCIÓN LEGISLATIVA}

Sin remontarnos a sus orígenes más remotos ${ }^{11}$, basta con apuntar que, a principios de los años setenta del siglo pasado, en Estados Unidos se le puso nombre a este fenómeno para hacer referencia a aquellos informantes internos que denunciaban posibles infracciones cometidas en el seno de la administración sobre cuestiones relacionadas con salud pública, seguridad, corrupción o abusos de poder ${ }^{12}$. En ese periodo, a consecuencia de una serie de factores sociopolíticos marcados por la corrupción y falta de ejemplaridad pública ${ }^{13}$, la administración

blica\%20Whistleblowers\%205\%20ENE\%2021.pdf>. Acceso en:23 02/2021). 23 feb. 2021.

11 Para una aproximación histórica de este fenómeno vid. BUCY, Pamela. Information as a commodity in the regulatory world. Houston Law Review Houston,vol. 39, issue 4, 2002, pp. 909-916.

12 ANN JOHNSON, Roberta. Whistleblowing: When it Works-and Why, Boulder: Lynne Rienner, 2003, p. 4.

13 Como apunta RAGUÉS I VALLÈS, la irrupción de este fenómeno "está muy vinculada con el movimiento de defensa de los derechos civiles, la desilusión 
estadounidense implementó medidas dirigidas básicamente a proteger a los delatores frente a posibles represalias ${ }^{14}$.

Ya a principios de este siglo, como consecuencia del escándalo del caso "Enron" ${ }^{15}$, se promulgaron en Estados Unidos nuevas leyes dirigidas a mejorar el control de las administraciones públicas y de las corporaciones privadas, en concreto de las sociedades cotizadas. A tal efecto, se dictó la Sarbanes-Oxley Act que, en su sección 806, bajo el rótulo "Protection for employees of publicly traded companies who provide evidence of fraud", incorporó varias medidas dirigidas a proteger a los empleados a fin de que se sintieran seguros a la hora de revelar posibles infracciones que hubieran podido cometer las corporaciones para las que trabajaban ${ }^{16}$. A raíz de este impulso legislativo, la protección de los alertadores ha pasado a formar parte de la cultura estadounidense. Algo que, en buena medida, ha favorecido su expansión al resto del mundo ${ }^{17}$.

Aunque el origen de este fenómeno no se halle en España, la idea de implantar canales de denuncias en las organizaciones a fin de mejorar

ciudadana ante la guerra del Vietnam y el Watergate y la incapacidad de las empresas y la administración para contener los nuevos riesgos de la tecnología y la industria”. RAGUÉS I VALLÈS, Ramón. ¿Héroes o traidores? La protección de los informantes internos (whistleblowers) como estrategia político-criminal. InDret, Barcelona, n. 3/2006, pág. 4.

GARCÍA MORENO, Beatriz. Del whistleblower al alertador. La regulación europea de los canales de denuncia, Valencia: Tirant lo Blanch, 2020, pp. 38 y ss. Sobre el concepto del whistleblower vid. GARCÍA-MORENO, Beatriz. El concepto de alertador (o whistleblower). En: RODRÍGUEZ-GARCÍA, Nicolás; RODRÍGUEZ-LÓPEZ, Fernando (edits.). Compliance y responsabilidade de las personas jurídicas, Tirant lo Blanch, Valencia, 2021, págs. 443-447.

15 Puede verse un reportaje periodístico sobre este caso en: "Enron: el mayor escándalo financiero de la historia, tan grande como olvidado”, La vanguardia, 2 de diciembre de 2016. Disponible en: <https://www.lavanguardia. com/economia/20161202/412319658496/enron-quiebra-escandalo.html>. Acceso en: 25 feb. 2021.

MARTÍNEZ SALDAÑA, David, ABRIL MARTÍNEZ, Javier. RODRÍGUEZ CELADA, Enrique. y REYES RICO, Laia., La protección del whistleblower tras la Directiva (UE) 2019/1937. Análisis del nuevo marco jurídico desde la perspectiva del Derecho Laboral, Público, Penal y de Protección de Datos. Actualidad jurídica Uría Menéndez, Madrid, n. 53-2019, 2019, p. 28.

17 ANN JOHNSON, Roberta. Whistleblowing: When it Works-and Why. Boulder: Lynne Rienner, 2003, p. 4. 
la capacidad de detección y de prevención de la comisión de determinadas infracciones no es algo tan novedoso en nuestra cultura jurídica ${ }^{18}$. Aunque no tuviera eficacia normativa, el Código unificado de buen gobierno de las sociedades cotizadas del año 2006 ya recomendaba, por indicación de la Comisión Europea, "que las sociedades cotizadas encomienden al Comité de Auditoría el establecimiento y seguimiento de mecanismos de esa naturaleza, que protejan la identidad del denunciante e incluso, si se considera oportuno, permitan su anonimato". Posteriormente, en su versión de 2013, se puntualizó que estos mecanismos debían ser canales de denuncia ${ }^{19}$.

A nivel normativo, el primer atisbo de reconocimiento de los canales de denuncia lo encontramos en la Ley 10/2010, de 28 de abril, de prevención del blanqueo de capitales y de la financiación del terrorismo. Esta ley, en su art. 30 establece que "los sujetos obligados adoptarán las medidas adecuadas para mantener la confidencialidad sobre la identidad de los empleados, directivos o agentes que hayan realizado una comunicación a los órganos de control interno"20.

No obstante, como ha apuntado Morales Martín ${ }^{21}$, sin perjuicio de su regulación en alguna normativa sectorial ${ }^{22}$, la "popularización” en

18 Véase en este sentido el trabajo pionero de Ragués Vallès.

19 FERNÁNDEZ GONZÁLEZ, María Cristina. ¿Proteger o premiar al whistleblower?: Un debate pendiente en España, GONZÁLEZ GARCÍA, Nicolás y CARRIZO GONZÁLEZ-CASTELL, Adán. Corrupción: Compliance, Represión y Recuperación de Activos Valencia: Tirant lo Blanch, 2019, versión digital.

20 En la versión vigente de la ley, tras la reforma de 2018, se incorporó el art. 26 bis que prevé el establecimiento por parte de los sujetos obligados de "procedimientos internos para que sus empleados, directivos o agentes puedan comunicar, incluso anónimamente, información relevante sobre posibles incumplimientos de esta ley, su normativa de desarrollo o las políticas y procedimientos implantados para darles cumplimiento, cometidos en el seno del sujeto obligado".

21 MORALES MARTÍN, Tamara. Canal de denuncias interno (whistleblowing), ¿anónimos o no? Esa es la cuestión. Legal Today. 29 de agosto de 2018.Disponible en:<https://www.legaltoday.com/opinion/blogs/nuevas-tecnologias-blogs/blog-prodat/canal-de-denuncias-interno-whistleblowing-anonimos-o-no-esa-es-la-cuestion-2018-08-29/>. Acceso en: 2 mar. 2021.

22 Un ejemplo característico de canales de denuncias en normativas sectoriales lo encontramos en el ámbito de la seguridad nuclear. El art. 13 de la Ley 33/2007, de 7 de noviembre, de reforma de la Ley 15/1980, de 22 de abril, de 
España de los canales de denuncia se produjo gracias a la entrada en vigor de la Ley Orgánica 5/2010, de 22 de junio, por la que se modifica la Ley Orgánica 10/1995, de 23 de noviembre, del Código Penal, que incorporó la responsabilidad penal de las personas jurídicas en el ordenamiento jurídico español. Aunque en esos momentos el Código Penal todavía no mencionaba a los canales de denuncia, las empresas comenzaron a implantar sistemas de denuncias internos en el marco de los programas de compliance, como una medida más de control y de prevención de delitos. Con la reforma del Código Penal introducida por la Ley Orgánica $1 / 2015$, de 30 de marzo, se incorporó ya de forma expresa una mención a los canales de denuncia. En concreto, el art. 31.5 bis CP establece que los modelos de organización y gestión deberán imponer "la obligación de informar de posibles riesgos e incumplimientos al organismo encargado de vigilar el funcionamiento y observancia del modelo de prevención”, y el art. 31.1. b) bis que incorpora el deber de "supervisión, vigilancia y control" sobre la labor de los subordinados ${ }^{23}$.

A raíz de esta modificación legislativa, la Fiscalía General de Estado, en su Circular 1/2016, de 22 de enero, declaró que "la existencia de unos canales de denuncia de incumplimientos internos o de actividades ilícitas de la empresa es uno de los elementos clave de los modelos de prevención”. Si bien, como continúa apuntando esta circular "para que la obligación impuesta pueda ser exigida a los empleados resulta imprescindible que la entidad cuente con una regulación protectora específica del denunciante (whistleblower), que permita informar sobre incumplimientos varios, facilitando la confidencialidad mediante sistemas que la garanticen en las comunicaciones (llamadas telefónicas, correos

creación del Consejo de Seguridad Nuclear, establece una suerte de canal de denuncias ante cualquier hecho "conocido que afecte o pueda afectar al funcionamiento seguro de las mismas y al cumplimiento de la normativa vigente en materia de seguridad nuclear o protección radiológica".

${ }^{23}$ En este sentido, como ha apuntado MAGRO SERVET, "la adopción de un canal de denuncia cumple con estos deberes, de manera que favorece la implantación de una cultura de cumplimiento de la organización, como preconiza la jurisprudencia del TS (STS 154/2016, de 29 de febrero y STS 221/2016, de 16 de marzo)”. En: MAGRO SERVET, Vicente. ¿Por qué es recomendable un canal de denuncias interno en la empresa?. Diario La Ley, Madrid, n. 9586, de 4 de marzo de 2020, p. 3. 
electrónicos...) sin riesgo a sufrir represalias" ${ }^{24}$. Como ha puesto de manifiesto Ragués i Vallès, todo esto ha supuesto que, aunque no existe hoy día en España una obligación legal de contar en el sector privado con procedimientos internos de denuncia, "en la práctica, una entidad jurídica que no cuente con dicho procedimiento corre el riesgo de que -en caso de imputación penal- su modelo de prevención de delitos no sea visto con buenos ojos por parte del fiscal o del tribunal. De ahí que la inmensa mayoría de asesores en materia de cumplimiento normativo aconsejen a sus clientes la implantación de tales recursos"25.

Por último, merece ser destacado el art. 24 Ley Orgánica 3/2018, de 5 de diciembre, de Protección de Datos Personales y garantía de los derechos digitales (en adelante, LOPD), que prevé un régimen específico para el tratamiento de los datos personales obtenidos a través de los "sistemas de información de denuncias internas".

De forma paralela, algunas Comunidades Autónomas han aprobado leyes que, en mayor o en menor medida, regulan la implantación de canales de denuncias en el seno de sus respectivas administraciones. A tal efecto, las legislaciones autonómicas más relevantes que se ocupan de este fenómeno son ${ }^{26}$ :

- Comunidad Valenciana: Ley/2016, de 28 de noviembre, de la Agencia de Prevención y Lucha contra el Fraude y la Corrupción ${ }^{27}$.

24 Circular 1/2016, de 22 de enero, sobre la responsabilidad penal de las personas jurídicas conforme a la reforma del Código Penal efectuada por la Ley Orgánica 1/2015. Disponible en: <https://www.boe.es/buscar/doc.php?id=FIS-C-2016-00001>.Acceso en: 3 mar. 2021.

25 RAGUÉS I VALLÈS, Ramón. El tratamento jurídico de los denunciantes antes y después de la Directiva 2019/1937. La Ley Compliance Penal, Madrid, n.1, 2020, pág. 3.

26 VESTRI, Gabriele. Aproximación al sistema de "whistleblowing”. Un nuevo desafío para la Administración Pública española. Revista General de Derecho Administrativo, Madrid, n. 51, 2019.

27 En su art. 14.1. c) dispone que "La agencia deberá establecer procedimientos y canales confidenciales para la formulación de denuncias que garanticen la estricta confidencialidad cuando el denunciante invoque la aplicación del estatuto regulado en este artículo. Estos procedimientos y canales podrán ser también utilizados por los que ya hayan actuado como denunciantes para comunicar represalias u otras actuaciones lesivas derivadas de la presentación de la denuncia". 
- Castilla y León: Ley 2/2016, de 11 de noviembre, por la que se regulan las actuaciones para dar curso a las informaciones que reciba la Administración Autonómica sobre hechos relacionados con delitos contra la Administración Pública y se establecen las garantías de los informantes ${ }^{28}$.

- Islas Baleares: Ley 16/2016, de 9 de diciembre, de creación de la Oficina de Prevención y Lucha contra la Corrupción en las Illes Baleares ${ }^{29}$.

- Aragón: Ley 5/2017, de 1 de junio, de Integridad y Ética Públicas aprobada por las Cortes de Aragón ${ }^{30}$.

Por su actualidad, merece una especial mención la regulación de esta cuestión en la comunidad autónoma de Andalucía. El pasado mes de julio, el Boletín Oficial de la Junta de Andalucía publicó la Ley $2 / 2021$, de 18 de junio, de lucha contra el fraude y la corrupción en Andalucía y protección de la persona denunciante. Esta ley tiene por objeto, por un lado, "la creación de una Oficina Andaluza contra el Fraude y la Corrupción y la regulación del procedimiento a seguir por la misma para la investigación e inspección de los hechos que pudieran ser constitutivos de fraude, corrupción, conflicto de intereses o cualquier otra actividad ilegal que en detrimento de intereses públicos o financieros". Y, por otro lado, el establecimiento de "una Oficina Andaluza contra el Fraude y la Corrupción y la regulación del

28 En sus tres artículos, establece una especie de canal externo de denuncias para la administración autonómica, designando como organismo receptor de las denuncias a la Inspección General de Servicio. Además, ofrece una serie de garantías para proteger a los denunciantes.

29 Esta Ley tiene por objeto la creación de una Agencia de Prevención y Lucha contra la Corrupción que se encarga entre otras cosas de gestionar las denuncias de corrupción bajo determinadas garantías.

30 Muy similar a la anterior. No obstante, en este caso regula con mayor detalle los canales de denuncias. En su art. 46 establece que "no se admitirán denuncias anónimas. No obstante, la Agencia deberá establecer procedimientos y canales confidenciales para la formulación de denuncias que garanticen su estricta confidencialidad cuando el denunciante invoque la aplicación del estatuto regulado en este artículo. En particular, la Agencia creará una oficina virtual, que pondrá a disposición de los denunciantes para la presentación de denuncias y documentación asociada, así como para la comunicación con los denunciantes que así lo soliciten, de manera segura y confidencial. Dichos procedimientos y canales podrán ser también utilizados por quienes ya hubiesen actuado como denunciantes para comunicar represalias u otras actuaciones lesivas derivadas de la presentación de la denuncia”. 
procedimiento a seguir por la misma para la investigación e inspección de los hechos que pudieran ser constitutivos de fraude, corrupción, conflicto de intereses o cualquier otra actividad ilegal que vaya en detrimento de intereses públicos o financieros, en los términos descritos en el Título I" (art. 1.2).

De todo lo expuesto hasta el momento se deduce que, a falta de la trasposición de la Directiva, nuestro ordenamiento jurídico carece de una regulación general e integral de los canales de denuncias. Como ha apuntado Bachmaier Winter a este respecto, la regulación vigente "ni cubre todos los ámbitos ni proporciona suficiente claridad y seguridad jurídica para que los sujetos que en el contexto laboral tienen conocimiento de infracciones legales, se sientan seguros para dar el paso de informar de los mismos" $"$.

\section{LA DIRECTIVA (UE) 2019/1937 RELATIVA A LA PROTECCIÓN DE LAS PERSONAS QUE REPORTEN INFRACCIONES DEL DERECHO DE LA UNIÓN}

\subsection{AnTECEDENTES}

A nivel de Derecho de la Unión Europea, antes de la protección de la Directiva, la protección de los denunciantes era una cuestión que estaba regulada de forma fragmentada ${ }^{32}$. La regulación europea en los sectores de servicios financieros, seguridad del transporte, seguridad animal, seguridad de las redes o de información y protección del medio ambiente ya hacía mención, de forma más o menos explícita, a los sistemas de denuncias para garantizar el cumplimiento de estas normativas. Sin embargo, la Directiva da un salto cualitativo, ya que propone articular

31 BACHMAIER WINTER, Lorena. "Whistleblowing europeo y compliance: La Directiva EU de 2019 relativa a la protección de personas que reporten infracciones del Derecho de la Unión”, Diario La Ley, Madrid, n. 9539, de 18 de diciembre de 2019, p. 3.

32 GARRÓS FONT, Imma, ROMERA SANTIAGO, Nuria. Hacia una protección efectiva de los denunciantes. Actualidad Administrativa, Madrid, n. 7-8, julio-agosto 2020, p. 50. 
un instrumento común y transversal para hacer frente al fraude y a la corrupción a nivel europeo ${ }^{33}$.

Para algún autor, la génesis de la Directiva se encuentra en la Comunicación de la Comisión "Derecho de la UE: mejores resultados gracias a una mejor aplicación” (2017/C 18/02) ${ }^{34}$. Ya en esta resolución, la Comisión ponía de relieve su preocupación por garantizar la aplicación efectiva del Derecho de la UE y reconocía "el papel crucial de las denuncias en la detección de las infracciones del Derecho de la UE”. A tal efecto, en su anexo fijaba una serie de recomendaciones para los "procedimientos administrativos para la gestión de las relaciones con el denunciante en relación con el Derecho de la Unión Europea”35.

A esta Comunicación de la Comisión le siguió la Resolución del Parlamento Europeo de 24 de octubre de 2017, sobre las medidas legítimas para la protección de los denunciantes de irregularidades que, en aras del interés público, revelan información confidencial sobre empresas y organismos públicos. En esta resolución, tras exponer una larga enumeración de considerandos sobre la importancia de proteger a los denunciantes de irregularidades en el marco de la Unión Europea, se declaró la necesidad de "establecer con carácter de urgencia un marco horizontal y exhaustivo que, mediante la formulación de derechos y obligaciones, proteja eficazmente a los denunciantes en los Estados miembros y en las instituciones, autoridades y organizaciones de la Unión" ${ }^{36}$. En este contexto, el 23 de abril de 2018, la Comisión Europea presentó una

33 SÁEZ LARA, Carmen. La protección de denunciantes: propuesta de regulación para España tras la Directiva Whistleblowing. Valencia: Tirant lo Blanch, 2020, p. 139.

34 KAFTERANIS, Dimitrios, A new enforcement tool: a directive to protect whistle-blowers. Business Law Review, vol. 41, issue 2, 2020, p. 50.

35 Comunicación de la Comisión. Derecho de la UE: mejores resultados gracias a una mejor aplicación (2017/C 18/02). Disponible en: < https://eur-lex. europa.eu/legal-content/ES/TXT/PDF/?uri=CELEX:52017XC0119(01)\&from=EN>Acceso en: 3 mar. 2021.

36 Resolución del Parlamento Europeo, de 24 de octubre de 2017, sobre las medidas legítimas para la protección de los denunciantes de irregularidades que, en aras del interés público, revelan información confidencial sobre empresas y organismos públicos (2016/2224(INI)). Disponible en: <https://www.europarl.europa.eu/doceo/document/TA-8-2017-0402_ES.html>. Acceso en: 3 mar. 2021. 
propuesta de directiva con el objetivo de "explorar plenamente el potencial de protección de quienes denuncian infracciones, con el fin de reforzar la aplicación de la legislación" 3738 .

Finalmente, y tras superar todos los trámites previstos para el procedimiento legislativo ordinario (arts. 289 y ss. TFUE), la Directiva se aprobó y se publicó en el Diario Oficial de la Unión Europea el 26 de noviembre de 2019.

\subsection{OBJeTIVOS Y ÁMBITO DE APLICACIÓN}

Como se deduce del considerando 1 de la Directiva, el legislador europeo parte de la siguiente premisa: las personas que trabajan para una organización son las primeras en tener conocimientos de las infracciones que se cometen en ella y, por lo tanto, deben desempeñar un papel protagonista a la hora de perseguir estas infracciones. Sin embargo, en la práctica, ante el temor a posibles represalias, los potenciales denunciantes no suelen llegar a informar sobre los posibles hechos ilícitos ${ }^{39}$.

37 Propuesta de Directiva del Parlamento Europeo y del Consejo relativa a la protección de las personas que informen sobre infracciones del Derecho de la Unión Disponible en: https://eur-lex.europa.eu/legal-content/ES/TXT/ HTML/?uri=CELEX:52018PC0218\&from=EN.Acceso en: 3 mar. 2021.

38 En realidad, como ha puesto de manifiesto algún autor, el Parlamento Europeo ya había solicitado de forma reiterada, durante casi una década, la adopción de una normativa europea que protegiera a los alertadores. Sin embargo, ni la Comisión Europea ni el Consejo parecían por la labor de actuar en este sentido, quizás porque este asunto siempre se ha percibido como un tema delicado de cara a la opinión pública. Sin embargo, parece que algunos escándalos de corrupción -principalmente el caso "LuxLeaks" - facilitaron el cambio de orientación de la Comisión al respecto. Vid. ABAZI, Vigjilenca. The European Union Whistleblower Directive: A'Game Changer' for Whistleblowing Protection. Industrial Law Journal, vol. 49, Issue 4, 2020, pp. 1-2.

39 Considerando primero de la Directiva (UE) 2019/1937 del Parlamento Europeo y del Consejo de 23 de octubre de 2019. En este sentido, resulta muy interesante el resumen de la evaluación de impacto que acompaña a la propuesta de Directiva del Parlamento Europeo y del Consejo relativa a la protección de las personas que informen sobre infracciones del Derecho de la Unión. En su apartado A, bajo la pregunta de ¿Cuál es el problema que se afronta? se señala que "en determinados ámbitos, las infracciones del Derecho de la UE que pueden perjudicar el interés público son difíciles de desenmascarar 
Ante esta situación, se llega a la conclusión -considerando 5- de la necesidad de aprobar:

Normas mínimas comunes que garanticen una protección efectiva de los denunciantes en los que respecta a aquellos actos y ámbitos en los que sea necesario reforzar la aplicación del Derecho, en los que la escasez de denuncias procedentes de denunciantes sea un factor clave que repercuta en esa aplicación, y en los que las infracciones del Derecho de la Unión puedan provocar graves perjuicios al interés público.

Por otro lado $^{40}$, la Directiva trata de acabar con la dispersión normativa en este materia ${ }^{41}$, con la finalidad de ofrecer un marco mínimo común que sirva para paliar "la escasez de denuncias" en determinados "ámbitos en los que sea necesario reforzar la aplicación del derecho" y en los que "las infracciones del Derecho de la Unión puedan provocar graves perjuicios al interés público" ${ }^{* 2}$.

puesto que las pruebas son complicadas de obtener. La información comunicada por denunciantes con acceso a dichas pruebas puede ser crucial en esos casos. Por consiguiente, garantizar que los denunciantes se sientan seguros para comunicar las infracciones puede ayudar a la aplicación de las medidas de ejecución y reforzar su efectividad". Disponible en: $<$ https://eur-lex.europa.eu/legal-content/ES/TXT/PDF/?uri=CELEX:52018SC0117\&from=EN>. Acceso en: 19 mar. 2021.

Considerando 3 de la Directiva (UE) 2019/1937 del Parlamento Europeo y del Consejo de 23 de octubre de 2019. Disponible en: <https://www.boe.es/ doue/2019/305/L00017-00056.pdf>. Acceso en: 5 ago. 2021.

Considerando 4 de la Directiva (UE) 2019/1937 del Parlamento Europeo y del Consejo de 23 de octubre de 2019. Disponible en: <https://www.boe.es/ doue/2019/305/L00017-00056.pdf>. Acceso en: 5 ago. 2021.

De acuerdo con un informe publicado por Transparencia Internacional en el año 2020 ("Mapping the EU on legal whistleblower protection"), la mayoría de los Estados europeos no disponen de una legislación específica que proteja a los alertadores. Y, los que la tienen, regulan la cuestión de forma deficiente. Según este informe, los únicos Estados que ofrecen una "strong protection" a sus alertadores son: Reino Unido, Malta, Italia, Países Bajos, Irlanda y Francia. Disponible en:<https://www.transparency.nl/wp-content/ uploads/2019/04/Mapping-the-EU-on-Whistleblower-Protection-TI-NL. pdf $>$. Acceso en: 21 mar. 2021. 
A lo largo de sus ciento diez considerandos, el legislador europeo va dejando pistas sobre los ámbitos específicos en los que cree que es necesario reforzar la aplicación del derecho de la UE. Este desarrollo cristaliza en su art. 2.1. a), en el que establece el listado de ámbitos en los que se aplicará el régimen jurídico previsto en la directiva. A tal efecto, establece que será de aplicación cuando se informe sobre infracciones del Derecho de la Unión que se produzca en uno de los siguientes ámbitos: i) contratación pública; ii) servicios, productos y mercados financieros, y prevención del blanqueo de capitales y la financiación del terrorismo; iii) seguridad de los productos y conformidad; iv) seguridad del transporte; v) protección del medio ambiente; vi) protección frente a las radiaciones y seguridad nuclear, vii) seguridad de los alimentos y los piensos, sanidad animal y bienestar de los animales; viii) salud pública; ix) protección de los consumidores; $\mathrm{x}$ ) protección de la privacidad y de los datos personales, y seguridad de las redes y los sistemas de información.

En todo caso, como cláusula de cierre, el art. 2.1. b) y c) establece que la Directiva se aplicará cuando las infracciones afecten a los intereses financieros de la Unión y cuando se refieran a normas relativas al mercado interior.

Como se puede comprobar, el ámbito de aplicación material de la Directiva es muy amplio, ya que puede llegar a ser de aplicación en prácticamente todas las ramas del Derecho de la Unión ${ }^{43}$. Sin embargo, en principio, quedan excluidas de él las denuncias sobre infracciones de normas que no tengan su origen en la UE. Como vamos analizar infra, una de las cuestiones claves que deben decidir los Estados en la transposición de la Directiva es precisamente si amplían el ámbito de aplicación de la Directiva a infracciones del Derecho interno. Esta es una opción que, al menos en el caso de España, parece bastante factible ${ }^{44}$.

43 A este respecto, debemos tener en cuenta las exclusiones previstas en el art. .3.3, relativas a la protección de información clasificada, a la protección del secreto profesional de los médicos y abogados, el secreto de las deliberaciones judiciales y las normas de enjuiciamiento criminal.

44 LOZANO CUTANDA, Blanca. La directiva de protección del denunciante. Diario La Ley, Madrid, n. 9550, 2020, p. 3; CAMPANÓN GALIANA, Laura. Análisis de la Directiva (UE) 2019/1937 del Parlamento Europeo y del Consejo de 23 de octubre de 2019 (Whistleblowing), relativa a la protección de 
En cuanto a su ámbito personal de aplicación, basta ahora con apuntar que la Directiva no se dirige únicamente a los trabajadores de estas entidades stricto sensu, sino a un amplio abanico de sujetos que, de forma más o menos estrecha, han mantenido o prevén mantener una vinculación con la entidad. En este sentido, el art. 4 establece un listado de sujetos a los que le será de aplicación el régimen previsto en la Directiva. Para hacernos una idea de la amplitud de su ámbito de aplicación personal, cabe destacar, por ejemplo, la inclusión de accionistas y personas pertenecientes al órgano de administración, los voluntarios, los trabajadores en prácticas, así como las personas que todavía no hayan comenzado su relación laboral cuando las infracciones se refieran al proceso de selección o de negociación precontractual ${ }^{45}$.

Por último, debemos destacar que la Directiva se constituye como una lex generalis en materia de protección de las personas que informen sobre infracciones del Derecho de la Unión, actuando de forma supletoria respecto de las normas especiales que existan o puedan llegar a existir para proteger a los alertadores, como ocurre en el caso del blanqueo de capitales ${ }^{46}$.

\subsection{CONTENIDO}

De acuerdo con los objetivos perseguidos, la Directiva establece un conjunto heterogéneo de medidas de diversa naturaleza. Sin ánimo de exhaustividad, en este apartado vamos a analizar algunas de las más importantes.

las personas que informen sobre infracciones del Derecho de la Unión. Carta Tributaria. Revista de Opinión, Madrid, n. 59, 2020, p. 5.

45 Como ha apuntado STAPPERS “The Whistleblower Protection Directive implicates that enforcement of EU law can only be effective if protection is granted to the broadest possible range of cate- gories of persons who have privileged access to information on breaches of EU law”. En: STAPPERS, Jan Tadeusz. EU Whistleblower Protection Directive: Europe on Whistleblowing. ERA Forum: Journal of the Academy of European Law, 2021, p. 6.

46 ABAZI, Vigjilenca. The European Union Whistleblower Directive: A'Game Changer' for Whistleblowing Protection. Industrial Law Journal, vol. 49, issue 4, 2020, p. 5. 


\section{a) Canales internos de denuncia}

La medida más llamativa, y quizás la que más relevancia tenga en la práctica, es la que se refiere a la obligación de instaurar canales internos de denuncia en el seno de las "entidades jurídicas" públicas y privadas (art. 8).

Con carácter general, un canal de denuncias interno se puede definir como aquel canal de comunicación directo establecido en el seno de una organización para que los empleados, clientes o proveedores puedan acudir a él para denunciar las infracciones tanto de normas internas como de otras regulaciones que rigen las actividades de las empresas ${ }^{47}$. Al tratarse de canales internos, su característica principal es que el receptor de la información es la corporación o, más bien, los responsables designados específicamente para tal fin ${ }^{48}$.

La Directiva no establece un concepto de canal de denuncia pero sí se preocupa de garantizar que estos sean "efectivos, confidenciales y seguros” ${ }^{49}$ para los alertadores. A tal efecto, en su art. 9 se encarga de regular cómo han de ser los procedimientos de denuncia interna y su seguimiento, para que se considere satisfecha la obligación impuesta por el artículo que le precede.

El primer requisito se refiere a la seguridad del canal. Según el art. 9.1 a) estos deben ser "diseñados, establecidos y gestionados de una forma segura que garantice que la confidencialidad de la identidad del denunciante y de cualquier tercero mencionado en la denuncia esté protegida, e impida el acceso a ella al personal no autorizado". En cuanto al funcionamiento del canal, se exige que se dé acuse de recibo al alertador [art. 9.1.b)] y que se designe a una persona o departamento "imparcial" para realizar el seguimiento diligente de las denuncias [art. 9.1. c) y d)]. Asimismo, se establece la obligación de dar una respuesta en un plazo razonable -nunca más de tres meses-.

47 PUYOL, Javier, El funcionamiento práctico del canal de compliance "whistleblowing". Valencia: Tirant lo Blanch, 2017, p. 9.

48 GARCÍA-MORENO, Beatriz. Del whistleblower al alertador: la regulación europea de los canales de denuncia, Valencia: Tirant lo Blanch, 2020, p. 67.

49 Considerando 3 de la Directiva 2019/1937. 
La Directiva, a fin de modular esta nueva carga para empresas que operan en la Unión, ha optado por exonerar de esta obligación a aquellas entidades jurídicas del sector privado de tamaño reducido, en concreto, a

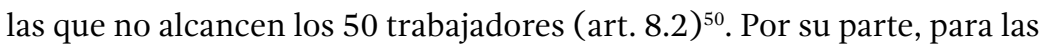
entidades del sector público, el art. 8.9 habilita a los Estados miembros a eximir de esta obligación a los municipios de menos de 10.000 habitantes o con menos de 50 trabajadores.

Por último, el art. 9.2 permite que la información se comunique de forma escrita o verbalmente, siendo posible en este último caso la utilización de un buzón telefónico u otros sistemas de mensajería. Aunque el artículo no diga más al respecto, el considerando 53 habla de la posibilidad de implantar estos canales a través de "una plataforma en línea, ya sea en la intranet o en internet”. Nos parece que esta vía es la más adecuada y, probablemente, la que gozará de una mayor implantación, especialmente en aquellas organizaciones que cuenten con una intranet.

\section{B) Canales externos de denuncia y ReVelación pública de la INFormación}

A pesar de que la instauración de estos canales internos sea quizás lo más llamativo de la Directiva, esta no solo impulsa la alerta interna ${ }^{51}$. También prevé la comunicación directa a las autoridades -canales de denuncias externos- que la regula con detalle en el capítulo III, y la revelación pública de la información (art. 15). Aunque en los considerandos parezca apostar de forma prioritaria por los canales internos de denuncia, en el art. 10 de la Directiva no consagra esa preferencia, ya que permite a los alertadores acudir a los canales externos tras haber comunicado la información "en primer lugar a través de los canales de denuncia interna, o bien comunicándola directamente a través de los canales de denuncia externa" ${ }^{2}$. De esta forma, implícitamente la Directiva parece reconocer

50 Salvo a las entidades a las que se refieren las partes I.B y II del anexo que, en todo caso, deberán instaurar los canales de denuncias internos (art. 8.3).

51 GARCÍA-MORENO, Beatriz, Del whistleblower al alertador. La regulación europea de los canales de denuncia, Valencia: Tirant lo Blanch, 2020,p. 60.

52 En el considerando 33 señala que, con carácter general, los alertadores "se sienten más cómodos denunciando por canales internos, a menos que tengan 
el derecho de los alertadores a elegir el tipo de canal de denuncia que consideren más adecuado en función de las circunstancias particulares del caso (considerando 33).

Sin perjuicio de esta idea, el art. 7.2 ordena a los Estados miembros que promuevan la comunicación interna frente a la externa siempre que, a juicio del alertador, la denuncia pueda tratarse internamente de manera efectiva y considere que no hay riesgo de represalias. En este punto, DE ZWART ha identificado tres escenarios en los que esta situación se podría dar: (i) la organización no ha implantado un canal interno de denuncias o lo ha implantado de forma inapropiada, (ii) el alertador tiene motivos para pensar que si usa el canal interno puede sufrir represalias o cuando (iii) el alertador considera que las autoridades competentes están en una mejor posición para tomar las medidas adecuadas ${ }^{53}$. Habrá que ver la forma en la que los Estados miembros articulan esta exigencia sin privar a los alertadores de su libertad de elección.

En cuanto a la gestión de este tipo de canales, el art. 11 hace responsable a los Estados de la designación de las autoridades competentes para recibir las denuncias, y establece una serie de principios que deberán regir en el funcionamiento de estos canales, principios que son muy similares a los previstos para los canales internos (independencia, autonomía, diligencia en la tramitación, respuesta en un plazo razonable, etc. $)^{54}$.

Cabe destacar que, en virtud de las disposiciones generales previstas en el Capítulo $\mathrm{V}$-Disposiciones aplicables a las denuncias internas y externas-, tanto los canales de internos de denuncia como los externos deben garantizar que no se revele la identidad del alertador (art. 17) y un tratamiento de datos personales de conformidad con el Reglamento (UE) 2016/679 (art. 18). Asimismo, las entidades jurídicas deberán llevar un registro de todas las denuncias recibidas. Este registro deberá cumplir con una serie de garantías dirigidas fundamentalmente a garantizar la confidencialidad de los alertadores y, en él, se conservarán las denuncias

motivos para denunciar por canales externos".

53 DE ZWART, Alja Poler. EU whistleblowing rules to change in favor of whistleblowers. Journal of investment compliance, vol. 21, n. 1, 2020, p. 57.

${ }^{54}$ GARRÓS FONT, Imma y ROMERA SANTIAGO, Nuria. Hacia una protección efectiva de los denunciantes. Actualidad Administrativa, Madrid, n. ${ }^{\circ} 7-8$, julio-agosto 2020, p. 5. 
durante el tiempo que sea necesario y proporcionado para cumplir con los requisitos previstos en las Directiva y en el Derecho de la Unión.

Por último, como una suerte de recurso de ultima ratio, la Directiva prevé en su art. 15 la revelación pública, que permite al alertador poner la información a disposición del público usando cualquier instrumento que le sirva a tal efecto (ej. redes sociales, medios de comunicación, plataformas web, etc. $)^{55}$. Como es lógico, para que el individuo que lleve a cabo la revelación sea considerado un alertador y pueda disfrutar de las garantías previstas en la Directiva, se exige que concurran una serie de circunstancias que justifique acudir a este cauce más "agresivo" para la organización ${ }^{56}$. En concreto, el art. 15.1 exige que se den algunos de las siguientes condiciones: a) que la persona haya denunciado primero por los canales de denuncias -interno o externos-, y no se hayan tomado las medidas apropiadas al respecto en el plazo marcado por la Directiva; b) que la persona tenga motivos razonables para pensar que la infracción supone un peligro “inminente o manifiesto para el interés público", que el cauce de la denuncia externa -en el caso de que ese sea el adecuado- no presenta las debidas garantías y pueda suponer un riesgo de represalias o que las autoridades responsables del canal puedan estar en "connivencia" con el autor de la infracción o implicada en la misma.

Por lo tanto, la revelación pública se configura como un cauce subsidiario y excepcional, ya que su uso solo será admisible desde el punto de vista de la Directiva en situaciones de ineficacia -involuntaria o premeditada- de los canales internos y externos de denuncias en situaciones de emergencia por motivos de interés público y en supuestos

55 LOZANO CUTANDA, Blanca. La directiva de protección del denunciante. Diario La Ley, Madrid, n. 9550, 2020, p. 8.

56 Como explica AMERIGO ALONSO, aunque las tres vías de comunicación previstas por la Directiva -canal interno, canal externo y revelación públicano operan necesariamente de forma sucesiva "sí existe una clara preferencia por la observancia de este orden, de modo que, para la renuncia a utilizar alguno de los cauces previos, el denunciante ha de tener motivos razonables que justifiquen su decisión, como que considere que hay riesgo de represalias si acude a los canales internos o que procede desechar los canales externos ante el temor de que puedan ocultarse o destruirse pruebas”. En: AMERIGO ALONSO, José. Los retos de la transposición de la Directiva Whistleblowing. Diario La Ley, Madrid, n. ${ }^{0}$ 9699, 2020, p. 3. 
de corrupción en los que la autoridad responsable del canal externo pueda estar implicada. En estos dos últimos supuestos, aunque nos parece lógica su inclusión, entendemos que su apreciación tiene un fuerte componente subjetivo, ya que el alertador difícilmente va a estar en condiciones de valorar adecuadamente si existe un "peligro inminente o manifiesto para el interés público", o que efectivamente existe "connivencia" por parte de la autoridad encargada del canal externo. Por este motivo, la Directiva únicamente exige que el alertador tenga "motivos razonables" para pensar que concurren una de estas dos circunstancias.

\section{c) MedidAs de PROTECCIÓN}

Más allá de potenciar la instauración de canales de denuncia efectivos, confidenciales y seguros, la Directiva tiene por objeto garantizar la protección de los alertadores frente a las represalias ${ }^{57}$. A tal efecto, en los arts. 19-22 se establece un sistema de garantías eminentemente laborales que insta a los Estados a tomar las medidas necesarias para evitar toda forma de represalias ${ }^{58}$. Aunque no tiene carácter cerrado, el art. 19 incluye un listado de represalias que puede ser de utilidad para comprender mejor el tipo de situaciones que la Directiva trata de erradicar. Así, por ejemplo, este artículo prohíbe toda amenaza o tentativa de represalia en forma de: suspensión, despido, destitución, degradación o denegación de ascenso, cambio de puesto de trabajo, denegación de formación, evaluación o referencias negativas con respecto a sus resultados laborales, imposición de medidas disciplinarias, etc.

Por su parte, en el art. 20 se establece una serie de medidas de apoyo para los alertadores, basadas en brindar información y asesoramiento completos e independientes sobre la protección que presta el ordenamiento jurídico, asistencia efectiva por parte de las autoridades competentes y, en su caso, asistencia jurídica en los procesos en los que se pueda ver involucrado el alertador -entendemos que por tal condición-.

57 Considerando 3 de la Directiva.

58 TORRENT I SANTAMARIA, Josep María y PÉREZ GIL DE GÓMEZ, Laura. Análisis de la Directiva Europea de whistleblowing y principales retos de la nueva regulación. El caso de España. Derecho PUCP, Lima, n. 85, 2020, p. 101. 
Por último, en el art. 21 se incorporan una serie de medidas de protección frente a represalias. De este precepto se deduce una preocupación del legislador europeo por exonerar de posibles responsabilidades a los alertadores que, en la obtención o difusión de la información, hayan cometido alguna infracción ${ }^{59}$.

Al mismo tiempo, incorpora una serie de medidas procesales tendentes a reforzar su posición. En este punto, nos parece especialmente relevante la inversión de la carga de la prueba a favor del alertador “represaliado". Establece el art. 21.5 que:

En los procedimientos ante un órgano jurisdiccional $\mathrm{u}$ otra autoridad relativos a los perjuicios sufridos por los denunciantes, y a reserva de que dicha persona establezca que ha denunciado o ha hecho una revelación pública y que ha sufrido un perjuicio, se presumirá que el perjuicio se produjo como represalia por denunciar o hacer una revelación pública. En tales casos, corresponderá a la persona que haya tomado la medida perjudicial probar que esa medida se basó en motivos debidamente justificados.

Como es lógico, únicamente tienen derecho a disfrutar de la protección que brinda la Directiva aquellos sujetos encuadrables en su ámbito de aplicación personal. Para ello, no solo es necesario que se den los requisitos del art. 4 antes comentado, sino también que concurran algunas

59 A este respecto, el art. 21.7 deja entrever el tipo de infracciones que el legislador europeo tiene en mente: "En los procesos judiciales, incluidos los relativos a difamación, violación de derechos de autor, vulneración de secreto, infracción de las normas de protección de datos, revelación de secretos comerciales, o a solicitudes de indemnización basadas en el Derecho laboral privado, público o colectivo, las personas a que se refiere el artículo 4 no incurrirán en responsabilidad de ningún tipo como consecuencia de denuncias o de revelaciones públicas en virtud de la presente Directiva. Dichas personas tendrán derecho a alegar en su descargo el haber denunciado o haber hecho una revelación pública, siempre que tuvieran motivos razonables para pensar que la denuncia o revelación pública era necesaria.

Cuando una persona denuncie o revele públicamente información sobre infracciones que entran en el ámbito de aplicación de la presente Directiva, y dicha información incluye secretos comerciales, y cuando dicha persona reúna las condiciones establecidas en la presente Directiva, dicha denuncia o revelación pública se considerará lícita en las condiciones previstas en el artículo 3, apartado 2, de la Directiva (UE) 2016/943. 
de las condiciones del art. 6. Por lo tanto, es preciso que el alertador "tenga motivos razonables para pensar que la información sobre infracciones denunciadas es veraz en el momento de la denuncia y que la citada información entra dentro del ámbito de aplicación de la presente Directiva" (art. 6.1). De esta forma, para gozar de la protección de la Directiva, no basta con verter cualquier información. Los alertadores, de acuerdo con las circunstancias y la información de la que dispongan, deben creer razonablemente que los hechos denunciantes son ciertos ${ }^{60}$-a este requisito se le ha denominado como el "estándar de la creencia razonable"-61. Además, se exige que se haya respetado el orden de preferencia previsto en la Directiva en el uso de los canales de información (art. 6.2) ${ }^{62}$.

\section{EL PROCESO DE TRANSPOSICIÓN DE LA DIRECTIVA AL ORDENAMIENTO JURÍDICO ESPAÑOL}

\subsection{La consulta pública para la transposición de la DiRectiva de 7 de ENERO DE 2021}

El período de transposición previsto para la Directiva finaliza con carácter general el próximo 17 de diciembre de 2021. Este plazo se ha excepcionado para las disposiciones relativas a las entidades jurídicas del sector privado que tengan de 50 a 249 trabajadores, para las que se

60 Como se ha destacado, con la elección de este criterio, la "protección no queda supeditada a la veracidad de la información, sino a la existencia de motivos razonables para confiar en ella”. En: AMERIGO ALONSO, José. Los retos de la transposición de la Directiva Whistleblowing. Diario La Ley, Madrid, n. 9699, 2020, p. 3.

61 SÁEZ LARA, Carmen. La protección de denunciantes: propuesta de regulación para España tras la Directiva Whistleblowing, cit. versión digital. Como ha señalado esta autora, la Directiva "no exige al informante una certeza absoluta acerca de la infracción que denuncia sino solo, como acontece en el modelo americano y británico, la razonable creencia o la razonable sospecha de que ello constituye una violación protegida".

62 CORONAS VALLE, Daniel. La nueva figura del Informante Protegido en la legislación europea: Evolución y Desafíos: Canales de Denuncia, Cumplimiento Normativo e Instituciones financieras. La Ley Mercantil, Madrid, n. 52, 2018, p. 6 . 
prevé un plazo de transposición más largo que finaliza el 17 de diciembre de 2023 (art. 26.1 y 2).

De acuerdo con el principio de trato más favorable y la cláusula de no regresión, los Estados miembros podrán introducir o mantener disposiciones más favorables para los derechos de los denunciantes que los establecidos en la Directiva (art. 25.1) y, en ningún caso, su aplicación podrá suponer una reducción del nivel de protección ya garantizado por los Estados miembros (art. 25.2) ${ }^{63}$. Por lo tanto, al elegir el mecanismo de la Directiva, la UE no ha apostado por una armonización total en esta materia. Cada Estado deberá optar entre ir más allá en la protección de los alertadores o "conformarse" con las normas mínimas previstas en la Directiva ${ }^{64}$.

En el caso de España, en el momento de la remisión de este trabajo nos encontramos en pleno proceso de transposición de la Directiva. Por ahora, no tenemos demasiada información al respecto, más allá de que se encuentra todavía en fase prelegislativa. El día 16 de junio de 2020 tuvo lugar la sesión constitutiva del grupo de trabajo que se está encargando de preparar la propuesta del texto articulado que transpondrá la Directiva ${ }^{65}$. Unos meses después, el 7 de enero de 2021, con el objeto de recabar la opinión de ciudadanos, organizaciones y asociación, el Ministerio de Justicia ha procedido a abrir el trámite de Consulta pública para la transposición de la Directiva ${ }^{66}$.

${ }^{63}$ Como ha apuntado GARCÍA MORENO, los Estados al transponer la Directiva "pueden extender la aplicación del texto a otras áreas para lograr un marco jurídico coherente y comprehensivo a nivel interno, pero la Directiva únicamente impone la obligación de crear canales de denuncia para reportar infracciones consumadas o planeadas del derecho de la Unión en ámbitos concretos". En: GARCÍA MORENO, Beatriz. Del whistleblower al alertador: la regulación europea de los canales de denuncia, Valencia: Tirant lo Blanch, 2020,pp. 59-60. DE ZWART, Alja Poler. EU whistleblowing rules to change in favor of whistleblowers. Journal of investment compliance, vol. 21, n. 1, 2020, p. 55. "Justicia avanza en la trasposición de la directiva europea que protege a los denunciantes de infracciones contra el interés público", ELDERECHO.COM (Lefebvre), 17 de junio de 2020 Disponible en: <https://elderecho.com/ justicia-avanza-la-trasposicion-la-directiva-europea-protege-los-denunciantes-infracciones-interes-publico>. Acceso en: 5 ago. 2021.

${ }_{66}$ Disponible en: <https://www.mjusticia.gob.es/en/areas-tematicas/actividad-legislativa/normativa/participacion-publica-proyectos-normativos/ proyectos-real-decreto>. Acceso en: 5 ago. 2021. 
Aunque el texto de la consulta pública no tenga valor jurídico, en él se dejan entrever algunos de los aspectos claves que se están discutiendo a la hora de elaborar el texto legislativo que traspondrá la Directiva a nuestro ordenamiento jurídico. Por lo tanto, a través del análisis de este documento podemos llegar a comprender mejor las dudas más relevantes que se están suscitando con su transposición.

A continuación, vamos a comentar brevemente las preguntas planteadas por la Secretaría General Técnica del Ministerio de Justicia en la citada consulta pública. Al mismo tiempo, expondremos algunas de las alegaciones realizadas por asociaciones y agencias públicas que han participado en este proceso, a fin de comprender mejor las posibles alternativas existentes. Aunque no se han publicado las aportaciones presentadas, algunas de estas entidades sí han publicado en sus páginas webs los documentos que han presentado en el proceso de consulta pública. A los efectos de este trabajo, hemos seleccionado tres de las aportaciones realizadas y publicadas, entendiendo que pueden resultar lo suficientemente representativas para sondear las posiciones de los actores interesados en la transposición de la norma. En concreto, nos referiremos a las aportaciones presentadas por la Oficina Antifraude de Cataluña ${ }^{67}$, por Transparency International España ${ }^{68}$, y las presentadas conjuntamente por Cumplen (Asociación de profesionales de Cumplimiento Normativo), IOC (Instituto de Oficiales de Cumplimiento) y WCA (World Compliance Association $)^{69}$.

67 Documento de la Oficina Antifraude de Cataluña. Disponible en:<https:// www.antifrau.cat/sites/default/files/Imatges/Premsa/Participaci\%C3\%B3n\%20en\%20consulta\%20p\%C3\%BAblica_Ley\%20transposicion\%20 Directiva\%20personas\%20alertadoras.pdf>. Acceso en: 5 ago. 2021.

68 Documento de Transparency International España. Disponible en: <https:// transparencia.org.es/wp-content/uploads/2021/02/ALEGACIONES-TI-E_ CONSULTA-PU\%CC\%81BLICA-SOBRE-LA-TRANSPOSICION-DIRECTIVA-UE-2019_1937-FINAL.pdf >. Acceso en: 5 ago. 2021.

69 Documento de Cumplen (Asociación de profesionales de Cumplimiento Normativo), IOC (Instituto de Oficiales de Cumplimiento) y WCA (World Compliance Association) Disponible en: <http://www.worldcomplianceassociation. ${ }^{\circ} \mathrm{com} / 3068 /$ noticia-la-world-compliance-association-presenta-su-propuesta-en-respuesta-a-la-consulta-publica-sobre-la-transposicion-de-la-directiva-ue-20191937.html>. Acceso en: 5 ago. 2021. 


\section{A) ÁMBito MATERIAL DE APLICACIÓN}

Como hemos comentado, la Directiva a la hora de fijar su ámbito de aplicación material solo se refiere a las infracciones del Derecho de la Unión. Por lo tanto, una de las cuestiones fundamentales que deben decidir los Estados a la hora su transposición es si ampliar o no la protección del denunciante a cualquier infracción del Derecho nacional más allá de la normativa europea ${ }^{70}$. Se trata de una opción que la propia Directiva prevé en su art. 2.2, al indicar que lo en él dispuesto se debe entender sin perjuicio de la facultad de los países para ampliar la protección en su Derecho nacional a otros ámbitos.

Las tres aportaciones que hemos consultado para esta investigación coinciden en señalar la conveniencia de ampliar el ámbito de aplicación material de la Directiva. Desde nuestro punto de vista, el argumento más sólido para defender esta opción es el que se expone en el documento de International Transparency España. Como señala esta entidad:

Un régimen de protección de denunciantes/alertadores que solo se aplique a las infracciones de algunos de los ámbitos de la legislación de la UE supondría un peso desproporcionado para dichos alertadores, los cuales se verían obligados a realizar necesariamente un juicio previo de subsunción del contenido de la denuncia para saber si ésta se encuentra incluida en alguno o algunos de los ámbitos a los cuales sí se les otorga protección y qué procedimiento seguir para poder gozar de la misma. De este modo, el resultado sería que, dada esta importante limitación, sólo se podrían detectar aquellas irregularidades e ilícitos que finalmente gozasen del ámbito de protección y se perderían aquellos otros que no lo están, socavando directamente el fin para el cual son creados este tipo de canales: prevenir y detectar todo tipo de prácticas ilícitas o delictivas e impedir que exista una protección fragmentada y parcial ${ }^{71}$.

70 En este sentido se plantean las dos primeras preguntas de la Consulta Pública: ¿Debe ampliarse la protección del denunciante a cualquier materia del Derecho nacional más allá de la normativa con origen en el Derecho europeo?; ¿En qué ámbitos o materias concretas la protección de los denunciantes necesita un mayor refuerzo?

71 Documento de Transparency International España. Disponible en: <https:// transparencia.org.es/wp-content/uploads/2021/02/ALEGACIO- 
De lo anterior se deduce que, al menos previsiblemente, la futura ley no solo se referirá a las infracciones del Derecho de la Unión, sino también a otras normativas que, por motivos de interés público, merezcan esta especial protección (ej. función pública, urbanismo, subvenciones, etc $)^{72}$.

\section{B) Ámbito personal de APLICACIÓN}

En lo relativo al ámbito personal de aplicación de la Directiva, la consulta pregunta sobre las entidades del sector público que deberían quedar integradas en él. A tal efecto, se cuestiona si se debe apostar por una concepción amplia del sector público como hace el art. 2 de la Ley 19/2013, de 9 de diciembre de transparencia, acceso a la información pública y buen gobierno. Y, en su caso, si se debería incluir a los órganos constitucionales y partidos políticos.

En este caso, también concuerdan las tres aportaciones analizadas. Todas ellas defienden un ámbito de aplicación amplio que permita implantar estos canales en cualquier tipo de entidad de derecho público con independencia de su estatuto jurídico. En este punto, nos parece muy acertada la posición de la Oficina Antifraude de Cataluña al defender que esa ampliación estaría especialmente justificada en el caso de los partidos políticos, que además de recibir fondos públicos, llevan a cabo actividades de riesgo desde el punto de vista de la corrupción, especialmente en lo que concierne a su financiación ${ }^{73}$.

NES-TI-E_CONSULTA-PU\%CC\%81BLICA-SOBRE-LA-TRANSPOSICIONDIRECTIVA-UE-2019_1937-FINAL.pdf>. Acceso en: 5 ago. 2021. p. 4.

72 Documento de la Oficina Antifraude de Cataluña, Disponible en: <https:// www.antifrau.cat/sites/default/files/Imatges/Premsa/Participaci\%C3\%B3n\%20en\%20consulta\%20p\%C3\%BAblica_Ley\%20transposicion\%20 Directiva\%20personas\%20alertadoras.pdf>. Acceso en: 5 ago. 2021. p. 3.

73 Documento de la Oficina Antifraude de Cataluña, Disponible en: <https:// www.antifrau.cat/sites/default/files/Imatges/Premsa/Participaci\%C3\%B3n\%20en\%20consulta\%20p\%C3\%BAblica_Ley\%20transposicion\%20 Directiva\%20personas\%20alertadoras.pdf>. Acceso en: 5 ago. 2021.p. 4. 


\section{c) Canales internos de denuncia}

Respecto de los canales internos de denuncia, la consulta se refiere a dos aspectos: los canales de denuncias anónimas y el alcance de la obligación para incorporar estos canales. Respecto de la primera cuestión, se pregunta si España debe acoger la opción de las denuncias anónimas y si, en su caso, esa posibilidad debería preverse tanto para el sector público como en el privado.

Esta es una de las cuestiones más delicadas a las que se enfrenta nuestro legislador a la hora de trasponer esta Directiva. A lo largo de su articulado, la Directiva exige la confidencialidad de los canales de denuncia, pero no que se garantice el anonimato. El anonimato se prevé como una opción para los Estados, que deben decidir si se exige a las entidades jurídicas que acepten y realicen el seguimiento de denuncias anónimas ${ }^{74}$.

Las aportaciones consultadas también confluyen en este punto. Las tres destacan la conveniencia de la admisión del anonimato, al considerar que puede suponer un incentivo muy importante para la utilización de estos canales. En este sentido, tanto en el documento de Transparency International España como en el de la Oficina Antifraude de Cataluña hacen mención a pronunciamientos jurisprudenciales y de organismos internacionales que parecen validar esta posibilidad.

Pese a la unanimidad en este punto, no nos parece tan claro que el legislador español vaya a asumir este criterio. Está claro que un canal de denuncia en el que se permite al alertador reservarse su identidad y no revelarla bajo ninguna circunstancia es más seguro desde la perspectiva del alertador. También es cierto que, oficiosamente, la obtención de información de fuentes anónimas siempre ha sido un recurso admitido por las autoridades al mando de la investigación criminal ${ }^{75}$. Y que, incluso

74 Como indica en su considerando 34: "debe ser posible para los Estados miembros decidir si se requiere a las entidades jurídicas de los sectores privado y público y a las autoridades competentes que acepten y sigan denuncias anónimas de infracciones que entren en el ámbito de aplicación de la presente Directiva”.

75 ORTIZ PRADILLO, Juan Carlos. La delación premiada en España: instrumentos para el fomento de la colaboración con la justicia. Revista Brasileira de Direito Processual Penal, Porto Alegre, vol. 3, n. 1, p. 43. 
la propia Ley Orgánica 3/2018, de 5 de diciembre, de Protección de Datos Personales y garantías de los derechos digitales en su art. 24 declara la licitud de los sistemas de información a través de los cuales pueda ponerse en conocimiento de una entidad de Derecho privado la comisión de infracciones de forma anónima. Sin embargo, no podemos obviar algunos de los inconvenientes que acarrea este tipo de denuncias. Más allá de las cuestiones éticas que se podrían suscitar y que escapan del ámbito de este trabajo, el anonimato puede fomentar las denuncias falsas con fines espurios y difamatorios ${ }^{76}$. Al mismo tiempo, puede tener efectos contraproducentes desde una perspectiva procesal. Por un lado, en fase de instrucción, la imposibilidad de tomarle declaración al alertador como testigo podría favorecer el sobreseimiento de la causa, especialmente en aquellos supuestos en los que el acervo probatorio sea escaso ${ }^{77}$. Y, por otro lado, en fase de juicio oral, la información vertida por el alertador no se podría hacer valer a través de ningún medio de prueba ${ }^{78}$. Desde nuestro punto de vista, estas circunstancias deberían ser por los menos valoradas por el legislador. Quizás se llegue a la conclusión de que el anonimato es la única forma de garantizar la eficacia de estos canales, sin embargo, creemos que antes se deberían explorar otras alternativas en las que se garantice la confidencialidad del alertador sin llegar al anonimato.

A este respecto, es interesante traer colación lo dispuesto sobre los canales de denuncias en el Anteproyecto de Ley de Enjuiciamiento Criminal aprobado el día 24 de noviembre de 2020 en el Consejo de

76 Comparte esta opinión: GARCÍA MORENO, Beatriz. Del whistleblower al alertador. La regulación europea de los canales de denuncia. Valencia: Tirant lo Blanch, 2020,p. 99.

77 En esta línea vid. TORRENT I SANTAMARIA, Josep Maria y PÉREZ GIL DE GÓMEZ, Laura. Análisis de la Directiva Europea de whistleblowing y principales retos de la nueva regulación. El caso de España. Derecho PUCP,Lima, n. 85, 2020, nota al pie 33 .

78 Admite esta circunstancia el documento de Transparency International España, al señalar que "su único inconveniente es que procesalmente no puede otorgársele más valor que el que realmente pueden tener como prueba de indicios dentro del proceso”. Documento de Transparency International España, Disponible en: <https://transparencia.org.es/wp-content/ uploads/2021/02/ALEGACIONES-TI-E_CONSULTA-PU\%CC\%81BLICA-SOBRE-LA-TRANSPOSICION-DIRECTIVA-UE-2019_1937-FINAL.pdf>. Acceso en: 3 abr. 2021.p. 7. 
Ministros. De acuerdo con la exposición de motivos, en el Anteproyecto se contempla "la posibilidad de que la denuncia derivada de la actuación, en el seno de una entidad pública o privada, de un alertador (...) pueda ser directamente presentada ante la autoridad penal competente por el responsable del canal de denuncia, no revelándose la identidad de la persona que dio la alerta interna salvo que se realice un requerimiento expreso al efecto". Esta idea se plasma en su art. 528.6 que, conforme a lo anunciado en la exposición de motivos, autoriza al responsable del canal de denuncias a comunicar a las autoridades la notitia criminis reservándose para sí la identidad del alertador, salvo que fuese requerido para hacerlo.

Sin perjuicio de las diversas cuestiones que se pueden suscitar en torno a este precepto -en el caso de que finalmente se convierta en ley-creemos que es interesante traerlo aquí porque su previsión nos hace pensar que el legislador (o, mejor, el prelegislador) da por sentado que los canales de denuncias serán confidenciales, pero no anónimos. De lo contrario, por más que se requiriera la revelación de la identidad, esta no se podría producir y la norma perdería su sentido.

Más allá del anonimato, en este apartado de la consulta también se pregunta sobre la extensión de la obligación para implantar canales internos de denuncia. En concreto, se formulan una serie de preguntas sobre la conveniencia de fijar esta obligación para entidades jurídicas que, en principio, no entrarían en el ámbito subjetivo de la Directiva ${ }^{79}$.

Más interesante nos parece la última pregunta del apartado 3, que se refiere a la idoneidad o no de permitir que los canales de denuncia puedan ser gestionados externamente por parte de un tercero, sin perjuicio de que la responsabilidad de la llevanza del canal sea del órgano interno de la compañía o entidad. En este punto, las aportaciones coinciden en admitir esa posibilidad. Sin embargo, no todas acogen esta opción con el mismo entusiasmo. A modo de ejemplo, en el documento conjunto de Cumplen, IOC y WCA, se defiende que esta se trata de una de las

79 ¿Qué sujetos deberían cumplir con la obligación de establecer canales y/o mecanismos de denuncia interna? ¿Debe España asegurarse que las entidades privadas de menos de 50 trabajadores establezcan mecanismos y/o canales de denuncia internos? ¿En qué sectores concretos debería garantizarse especialmente el cumplimiento por parte de las empresas de disponer de canales de denuncia internos? 
actividades "más susceptibles de externalización" dentro de los programas de cumplimiento normativo ${ }^{80}$. Mientras que para la Oficina Antifraude de Cataluña esta opción debería descartarse en el sector público y controlarse en el privado ${ }^{81}$.

\section{D) Canales externos de denuncia}

En cuanto a los canales externos de denuncia, la consulta pública pone el foco en incorporar la posibilidad de archivo del procedimiento en dos escenarios: en los casos de infracciones menores y en aquellos en los que las infracciones denunciadas no contengan información nueva respecto de otras ya denunciadas anteriormente.

Los documentos analizados comparten que el archivo, si se introduce, se ha de hacer de forma muy pautada. En este punto, merece ser destacada la aportación de International Transparency España. Destaca en su documento que en ningún caso se debería establecer un "criterio de oportunidad" a la hora de decretar el archivo por parte del responsable del canal, sino que se podría fijar un elenco de conductas que, por su escaso o insignificante desvalor social, no fuera merecedor de iniciar un expediente ${ }^{82}$.

En lo que se refiere al segundo escenario, las aportaciones tampoco se oponen al reconocimiento del archivo, siempre con las cautelas oportunas. Como señala la Oficina Antifraude de Cataluña, la previsión de

80 Documento presentado por Cumplen (Asociación de profesionales de Cumplimiento Normativo), IOC (Instituto de Oficiales de Cumplimiento) y WCA, Disponible en: <http://www.worldcomplianceassociation. ${ }^{\circ} \mathrm{com} / 3068 / \mathrm{no}^{-}$ ticia-la-world-compliance-association-presenta-su-propuesta-en-respuesta-a-la-consulta-publica-sobre-la-transposicion-de-la-directiva-ue-20191937.html>. Acceso en: 3 abr. 2021.p. 4.

81 Documento de la Oficina Antifraude de Cataluña, Disponible en: <https:// www.antifrau.cat/sites/default/files/Imatges/Premsa/Participaci\%C3\%B3n\%20en\%20consulta\%20p\%C3\%BAblica_Ley\%20transposicion\%20 Directiva\%20personas\%20alertadoras.pdf>. Acceso en: 3 abr. 2021.p. 9.

82 Documento de Transparency International España, Disponible en: <https:// transparencia.org.es/wp-content/uploads/2021/02/ALEGACIONES-TI-E_ CONSULTA-PU\%CC\%81BLICA-SOBRE-LA-TRANSPOSICION-DIRECTIVA-UE-2019_1937-FINAL.pdf>.Acceso en: 3 abr. 2021.p. 12. 
esta posibilidad no obsta para el reconocimiento "de ciertos derechos a la persona alertadora, a efectos de audiencia o de la posibilidad de recurrir el archivo por falta de diligencia en la tramitación o falta de consideración de factores relevantes" ${ }^{83}$.

\section{E) AUTORIDADES COMPETENTES ENCARGADAS DE LOS CANALES EXTERNOS DE DENUNCIA}

En este apartado, la consulta pregunta abiertamente sobre la idoneidad de crear una autoridad administrativa independiente encargada de recibir, dar respuesta y seguir las denuncias que se presenten por canales externos o si sería preferible atribuir esta función a una autoridad ya existente. En este punto, la Directiva no se pronuncia, dejando así total libertad a los Estados para que atribuyan esta competencia al órgano administrativo que estimen conveniente.

En el ámbito comparado, algunos Estados han optado por la creación de Agencias Nacionales Anticorrupción que previsiblemente asumirán también esta competencia (ej. Italia). En España, no tenemos una entidad de estas características, aunque algunas comunidades autónomas sí que las han creado para su ámbito competencial. Desde nuestro punto de vista, este es un modelo que puede resultar interesante, aunque para nada imprescindible. Esta función puede ser desempeñada perfectamente, por ejemplo, por la Fiscalía Especial contra la Corrupción y la Criminalidad Organizada, para el caso de las infracciones constitutivas de delito ${ }^{84}$.

En cualquier caso, para nosotros, más allá de la cuestión orgánica, lo importante es que las entidades que finalmente se encarguen de recibir, dar respuesta y seguir las denuncias que se presenten en los canales

83 Documento de Transparency International España, Disponible en: <https:// transparencia.org.es/wp-content/uploads/2021/02/ALEGACIONES-TI-E_ CONSULTA-PU\%CC\%81BLICA-SOBRE-LA-TRANSPOSICION-DIRECTIVA-UE-2019_1937-FINAL.pdf>.Acceso en: 3 abr. 2021.p. 12.

84 Documento de Cumplen (Asociación de profesionales de Cumplimiento Normativo), IOC (Instituto de Oficiales de Cumplimiento) y WCA, Disponible en: <http://www.worldcomplianceassociation. ${ }^{\circ} \mathrm{com} / 3068 /$ noticia-la-world-compliance-association-presenta-su-propuesta-en-respuesta-a-la-consulta-publica-sobre-la-transposicion-de-la-directiva-ue-20191937.html>. Acceso en: 3 abr. 2021.p. 4 . 
externos, den cumplimiento a las garantías que prevén los arts. 15 y ss. de la Directiva.

\section{F) Sanciones}

En relación con las sanciones, el apartado sexto de la consulta pregunta sobre el tipo de sanciones a utilizar frente a las infracciones de la Directiva. En este punto, la Directiva únicamente exige que las sanciones sean efectivas, proporcionadas y disuasorias, dejando su configuración a los Estados.

Los documentos analizados coinciden en apuntar que se deberán prever sanciones de diversa naturaleza en atención del bien jurídico protegido. La Oficina Antifraude de Cataluña señala que "deberían considerarse las sanciones económicas, amonestación, declaración del incumplimiento y publicidad en algunos casos" ${ }^{85}$, llegando incluso a proponer "la pena de prisión para las modalidades más graves" ${ }^{86}$.

Por otro lado, se propone también la regulación de las consecuencias civiles y laborales de las infracciones, como puede ser la responsabilidad civil por daños y perjuicios ${ }^{87}$ o la nulidad de las cláusulas contractuales que vulneren derechos reconocidos en la ley ${ }^{88}$.

85 Documento de la Oficina Antifraude de Cataluña<https://www.antifrau.cat/ sites/default/files/Imatges/Premsa/Participaci\%C3\%B3n\%20en\%20consulta\%20p\%C3\%BAblica_Ley\%20transposicion\%20Directiva\%20personas\%20 alertadoras.pdf>. Acceso en: 3 abr. 2021. p. 13.

86 Documento de la Oficina Antifraude de Cataluña, Disponible en: <https:// www.antifrau.cat/sites/default/files/Imatges/Premsa/Participaci\%C3\%B3n\%20en\%20consulta\%20p\%C3\%BAblica_Ley\%20transposicion\%20 Directiva\%20personas\%20alertadoras.pdf>. Acceso en: 5 ago. 2021. p. 13.

87 Documento de Cumplen (Asociación de profesionales de Cumplimiento Normativo), IOC (Instituto de Oficiales de Cumplimiento) y WCA, Disponible en: <http://www.worldcomplianceassociation. ${ }^{\circ} \mathrm{com} / 3068 /$ noticia-la-world-compliance-association-presenta-su-propuesta-en-respuesta-a-la-consulta-publica-sobre-la-transposicion-de-la-directiva-ue-20191937.html>. Acceso en: 5 ago. 2021.p. 5.

88 Documento de la Oficina Antifraude de Cataluña, cit. p<https://www.antifrau.cat/sites/default/files/Imatges/Premsa/Participaci\%C3\%B3n\%20 en\%20consulta\%20p\%C3\%BAblica_Ley\%20transposicion\%20Directiva\%20 personas\%20alertadoras.pdf>. Acceso en: 5 ago. 2021. p. 13. 


\section{G) Premios o Recompensas}

Por último, se pregunta sobre la posibilidad de incluir premios o recompensas para los alertadores. Se trata, sin duda, de uno de los aspectos más problemáticos de los sistemas de denuncia y sobre el que la Directiva ni siquiera se pronuncia. En el modelo anglosajón, es habitual que se recompense la colaboración con la justicia. Es paradigmática en este sentido la legislación estadounidense, que prevé una recompensa para el alertador de hasta un $30 \%$ del total del dinero recuperado ${ }^{89}$.

Sobre este asunto, a pesar de reconocer las ventajas que conllevaría desde una perspectiva utilitarista la previsión de recompensas económicas para el alertador ${ }^{90}$, las aportaciones consultadas coinciden en descartar la concesión de premios que incentiven económicamente a los alertadores, por las nocivas consecuencias que podría tener en la sociedad ${ }^{91}$. Nos parece muy afortunada en este apartado la aportación de Transparency International España, al defender que "el actuar conforme a derecho no parece que se tenga que motivar por la existencia de "premios", sino por la verdadera convicción y compromiso con los valores éticos e institucionales en un Estado de Derecho"92.

89 FERNÁNDEZ GONZÁLEZ, María Cristina. “¿Proteger o premiar al whistleblower?: Un debate pendiente en España”, GONZÁLEZ GARCÍA, Nicolás y CARRIZO GONZÁLEZ-CASTELL, Adán. Corrupción: Compliance, Represión y Recuperación de Activos. Valencia: Tirant lo Blanch, 2019, versión digital.

90 Como apunta la Oficina Antifraude de Cataluña entre sus posibles ventajas está que "incentiva las alertas; aumenta la calidad en la información; cumple una función de prevención general (¿quién más puede estar observándome?); favorece la alerta como decisión económica racional; preserva la identidad del alertador; beneficia el erario público". En: Documento de la Oficina Antifraude de Cataluña, <https://www.antifrau.cat/sites/default/files/ Imatges/Premsa/Participaci\%C3\%B3n\%20en\%20consulta\%20p\%C3\%BAblica_Ley\%20transposicion\%20Directiva\%20personas\%20alertadoras.pdf >. Acceso en: 5 ago. 2021.p. 15.

91 Documento de Cumplen (Asociación de profesionales de Cumplimiento Normativo), IOC (Instituto de Oficiales de Cumplimiento) y WCA, Disponible en: <http://www.worldcomplianceassociation. ${ }^{\circ} \mathrm{com} / 3068 /$ noticia-la-world-compliance-association-presenta-su-propuesta-en-respuesta-a-la-consulta-publica-sobre-la-transposicion-de-la-directiva-ue-20191937.html>. Acceso en: 5 ago. 2021.p. 5.

92 Documento de Transparency International España, Disponible en: <https://transparencia.org.es/wp-content/uploads/2021/02/ALEGACIO- 


\subsection{Breve referencia al proceso de transposición de la Directiva en OtROS ESTADOS MIEMBROS}

Aunque este trabajo tenga por objeto la transposición de la Directiva al ordenamiento jurídico español, no está de más referirnos brevemente al estado en el que se encuentra el proceso de transposición de la Directiva en otros Estados miembros al momento de suscribir estas líneas -agosto del 2021-y, en su caso, comentar algunos de los resultados más relevantes.

De acuerdo con la Whistleblowing Laws in Europe: An international guide publicada por DLA Piper el pasado mes de junio ${ }^{93}$, el nivel de implementación de la Directiva no es muy elevado, a pesar de que el período de transposición previsto vence con carácter general el próximo 17 de diciembre de 2021. De los 27 Estados miembros, solo 6 se encuentran en una fase avanzada del proceso de transposición -República Checa, Dinamarca, Irlanda, Holanda, Portugal, Suecia-. Otros 6 se sitúan en un estado intermedio -Francia, Alemania, Italia, Rumanía, Eslovaquia y España-. Mientras que el resto, o están iniciando ahora el proceso, o ni siquiera lo han empezado ${ }^{94}$.

Teniendo en cuenta esta circunstancia, hemos analizado los textos prelegislativos -y legislativos, en el caso de Dinamarca- que se están tramitando en los países que van más avanzados en el proceso de transposición, a fin de detectar posibles tendencias entre los legisladores europeos. Evidentemente, este análisis podría ser más exhaustivo, sin embargo, creemos que con la información expuesta es suficiente para ofrecer una panorámica de lo que se está haciendo en términos generales ${ }^{95}$.

NES-TI-E_CONSULTA-PU\%CC\%81BLICA-SOBRE-LA-TRANSPOSICIONDIRECTIVA-UE-2019_1937-FINAL.pdf>.Acceso en: 5 ago. 2021.p. 15.

93 Disponible en < https://www.dlapiper.com/en/france/insights/publications/2021/06/whistleblowing-guide/>. Acceso 8 ago 2021.

94 También se puede consultar información sobre esta cuestión en: https:// www.polimeter.org/en/euwhistleblowing. Acceso en: 8 ago. 2021. También en: https://www.whistleblowingmonitor.eu/>. Acceso en: 9 de ago. 2021.

95 A la hora de elaborar la tabla hemos incluido básicamente los elementos que hemos considerado más relevante en la transposición de la Directiva al ordenamiento jurídico español. No obstante, hemos eliminado la mención a los premios y recompensas porque ninguno de los proyectos consultados los prevén. 


\begin{tabular}{|c|c|c|c|}
\hline & República Checa ${ }^{96}$ & Dinamarca $^{97}$ & Irlanda $^{98}$ \\
\hline $\begin{array}{l}\text { Ámbito } \\
\text { material }\end{array}$ & $\begin{array}{l}\text { Cualquier } \\
\text { infracción penal o } \\
\text { administrativa, tanto } \\
\text { del Derecho de la UE } \\
\text { como del Derecho } \\
\text { interno -limitado a } \\
\text { ciertas áreas-. }\end{array}$ & $\begin{array}{l}\text { Las infracciones del } \\
\text { Derecho de la UE a } \\
\text { las que se refiere la } \\
\text { Directiva, así como } \\
\text { otras infracciones } \\
\text { graves del Derecho } \\
\text { interno (con alguna } \\
\text { exclusión interesante } \\
\text { en materia de } \\
\text { seguridad nacional). }\end{array}$ & $\begin{array}{l}\text { Las infracciones del } \\
\text { Derecho de la UE } \\
\text { a las que se refiere } \\
\text { la Directiva, así } \\
\text { como prácticamente } \\
\text { cualquier infracción } \\
\text { del Derecho interno. }\end{array}$ \\
\hline $\begin{array}{l}\text { Obligación } \\
\text { de establecer } \\
\text { canales } \\
\text { internos de } \\
\text { denuncia }\end{array}$ & $\begin{array}{l}\text { Se extiende a: (i) } \\
\text { entidades sometidas } \\
\text { a la legislación sobre } \\
\text { contratación pública } \\
\text { (ii) entidades con al } \\
\text { menos } 25 \text { trabajadores } \\
\text { en los últimos cuatro } \\
\text { meses (iii) Entidades } \\
\text { autorizadas para } \\
\text { realizar préstamos } \\
\text { al consumo (iv) } \\
\text { Determinadas } \\
\text { sociedades } \\
\text { mercantiles (v) } \\
\text { Entidades públicas } \\
\text { que tengan por } \\
\text { objeto actividades } \\
\text { especialmente } \\
\text { sensibles. }\end{array}$ & $\begin{array}{l}\text { Se extiende con } \\
\text { carácter general a } \\
\text { todas las entidades } \\
\text { públicas y privadas } \\
\text { con } 50 \text { o más } \\
\text { trabajadores. }\end{array}$ & $\begin{array}{l}\text { Se extiende a todas las } \\
\text { entidades públicas o } \\
\text { privadas con } 50 \text { o más } \\
\text { trabajadores. }\end{array}$ \\
\hline
\end{tabular}

96 El proyecto de ley aprobado por el gobierno se puede consultar en el siguiente enlace: <https://apps.odok.cz/veklep-detail?pid=KORNBR3DRSYB>. Acceso en: 9 ago. 2021.

97 La Ley aprobada por el parlamento danés se puede consultar en: https:// www.retsinformation.dk/eli/ft/202013L00213>. Acceso en: 9 de ago. 2021.

98 La propuesta de reforma de la Draft Scheme of the Protected Disclosures aprobada por el Gobiernos Irlandés para transponer la Directiva puede consultarse en el siguiente enlace: < https://www.gov.ie/en/publication/ e20b61-protected-disclosures-act-guidance-for-public-bodies/\#eu-whistleblowing-directive>. Acceso en: 9 de ago. 2021. 


\begin{tabular}{|c|c|c|c|}
\hline & República Checa ${ }^{96}$ & Dinamarca $^{97}$ & Irlanda $^{98}$ \\
\hline $\begin{array}{l}\text { Canales } \\
\text { anónimos }\end{array}$ & $\begin{array}{l}\text { No se especifica } \\
\text { la posibilidad de } \\
\text { implantar canales } \\
\text { anónimos. }\end{array}$ & $\begin{array}{l}\text { No se especifica } \\
\text { la posibilidad de } \\
\text { implantar canales } \\
\text { anónimos. }\end{array}$ & $\begin{array}{l}\text { Se permite el } \\
\text { anonimato pero } \\
\text { se especifica que } \\
\text { "nothing in this } \\
\text { Act shall impose an } \\
\text { obligation on any of } \\
\text { the legal entities within } \\
\text { the scope of this Act } \\
\text { to accept and follow } \\
\text { up on anonymous } \\
\text { disclosures". }\end{array}$ \\
\hline $\begin{array}{l}\text { Autoridades } \\
\text { competentes } \\
\text { encargadas } \\
\text { de los canales } \\
\text { externos }\end{array}$ & Ministerio de Justicia. & $\begin{array}{l}\text { Ministerio de Justicia } \\
\text { y el de Defensa en } \\
\text { el ámbito de sus } \\
\text { competencias. }\end{array}$ & $\begin{array}{l}\text { Diversas entidades } \\
\text { públicas en función } \\
\text { del ámbito de } \\
\text { actuación. }\end{array}$ \\
\hline Sanciones & $\begin{array}{l}\text { Se prevé la imposición } \\
\text { de sanciones } \\
\text { administrativas } \\
\text { en caso de } \\
\text { incumplimiento. }\end{array}$ & $\begin{array}{l}\text { Se prevén sanciones } \\
\text { administrativas } \\
\text { e incluso penales } \\
\text { para las empresas } \\
\text { incumplidoras. }\end{array}$ & $\begin{array}{l}\text { El epígrafe } 24 \text { ordena } \\
\text { la imposición de } \\
\text { sanciones aducadas } \\
\text { para las personas } \\
\text { que obstaculicen } \\
\text { la denuncia, tome } \\
\text { represalias o } \\
\text { incumpla el deber de } \\
\text { confidencialidad. }\end{array}$ \\
\hline
\end{tabular}

TABLA 1 


\begin{tabular}{|c|c|c|c|}
\hline & Holanda ${ }^{99}$ & Portugal $^{100}$ & Suecia $^{101}$ \\
\hline $\begin{array}{l}\text { Ámbito } \\
\text { material }\end{array}$ & $\begin{array}{l}\text { Prácticamente } \\
\text { cualquier infracción } \\
\text { que pueda perjudicar } \\
\text { al interés público, así } \\
\text { como las infracciones } \\
\text { del Derecho de la } \\
\text { UE previstas en la } \\
\text { Directiva. }\end{array}$ & $\begin{array}{l}\text { Además de las } \\
\text { infracciones de } \\
\text { Derecho de la UE } \\
\text { previstas en la } \\
\text { Directiva, el art. } \\
\text { 1.d) de la propuesta } \\
\text { incorpora: "A } \\
\text { criminalidade violenta, } \\
\text { especialmente violenta } \\
\text { e altamente organizada, } \\
\text { bem como os crimes } \\
\text { previstos no n. } 1 \\
\text { do artigo } 1 . .^{\circ} \text { da Lei } \\
n .^{\circ} 5 / 2002, \text { de } 11 \\
\text { de janeiro, na sua } \\
\text { redação atual". En el } \\
\text { ámbito de la seguridad } \\
\text { nacional, el concepto } \\
\text { de infracción se limita } \\
\text { a los actos u omisiones } \\
\text { de las reglas de } \\
\text { contratación previstos } \\
\text { en la Directiva. }\end{array}$ & $\begin{array}{l}\text { Además de las } \\
\text { infracciones del } \\
\text { Derecho de la UE } \\
\text { previstas en la } \\
\text { Directiva, la ley } \\
\text { extiende su aplicación } \\
\text { a la información sobre } \\
\text { cualquier infracción } \\
\text { del derecho interno } \\
\text { en la que se vea } \\
\text { involucrado el interés } \\
\text { público, con exclusión } \\
\text { de las informaciones } \\
\text { relativas a la seguridad } \\
\text { nacional y de defensa. }\end{array}$ \\
\hline
\end{tabular}

99 La propuesta de transposición de la Directiva que se está tramitando en el parlamento neerlandés puede consultarse en el siguiente enlace: https:// www.tweedekamer.nl/downloads/document?id=561fe05a-3175-4931-a93b -37250026eb31\&title=Voorstel\%20van\%20wet.pdf. Acceso en: 9 ago. 2021.

${ }^{100}$ LapropostadeLein. ${ }^{\circ}$ 91/XIVpresentadaporelgobiernoyqueseestátramitandoenel parlamento puede consultarse en: <https://app.parlamento.pt/webutils/docs/ doc.pdf?path $=6148523063446 f 764 \mathrm{c} 324679626 \mathrm{~d} 56304 \mathrm{c} 334 \mathrm{e} 706447567 \mathrm{a}-$ 4c31684a566b786c5a79394562324e31625756756447397a5357357059326c$6864476 \mathrm{c} 325953387 \mathrm{a} 4 \mathrm{~d} 7 \mathrm{a} 4 \mathrm{e} 684 \mathrm{e} 4467784 \mathrm{f} 53307759574 \mathrm{e} 694 \mathrm{c}-$ $5451324 d 6 d 51744 \mathrm{f} 47566 a 4 \mathrm{e} 5330794 \mathrm{~d} 545 \mathrm{a} 6 \mathrm{~d} 5 \mathrm{a} 5751314 \mathrm{f} 5455314 \mathrm{e}-$ 6d51755a47396a65413d3d\&fich=333a4819-0acb-462d-8ec5-216fed59556d. docx\&Inline=true >. Acceso en: 14 ago. 2021.

${ }^{101}$ La propuesta de transposición de la Directiva que se está tramitando en el parlamento sueco puede consultarse en: < https://www.regeringen.se/49bcf4/ contentassets/1332545b2f4f4981b0b52a91a255fba6/genomforande-av-visselblasardirektivet.pdf >. Acceso en: 14 ago. 2021. 


\begin{tabular}{|c|c|c|c|}
\hline & Holanda ${ }^{99}$ & Portugal $^{100}$ & Suecia $^{101}$ \\
\hline $\begin{array}{l}\text { Obligación } \\
\text { de establecer } \\
\text { canales } \\
\text { internos de } \\
\text { denuncia }\end{array}$ & $\begin{array}{l}\text { Todas las entidades } \\
\text { públicas o privadas con } \\
50 \text { o más trabajadores. }\end{array}$ & $\begin{array}{l}\text { Personas jurídicas } \\
\text { públicas o privadas con } \\
50 \text { o más trabajadores. } \\
\text { Es interesante la } \\
\text { creación ex lege de } \\
\text { canales de denuncias } \\
\text { internos en el seno de } \\
\text { varias instituciones } \\
\text { del Estado (art. } \\
\text { 8.4) (Presidência da } \\
\text { República, Assembleia } \\
\text { da República, Tribunal } \\
\text { Constitucional, } \\
\text { Conselho Superior da } \\
\text { Magistratura, Conselho } \\
\text { Superior dos Tribunais } \\
\text { Administrativos e } \\
\text { Fiscais, o Tribunal de } \\
\text { Contas, a Procuradoria- } \\
\text { Geral da República). }\end{array}$ & $\begin{array}{l}\text { Las entidades públicas } \\
\text { o privadas que, } \\
\text { al inicio del año, } \\
\text { cuenten con } 50 \text { o más } \\
\text { trabajadores. }\end{array}$ \\
\hline $\begin{array}{l}\text { Canales } \\
\text { anónimos }\end{array}$ & $\begin{array}{l}\text { No se contempla } \\
\text { expresamente la } \\
\text { posibilidad de } \\
\text { implantar canales } \\
\text { anónimos } \\
102\end{array}$ & $\begin{array}{l}\text { Solo se reconoce esta } \\
\text { posibilidad para las } \\
\text { denuncias externas } \\
\text { (art. 14.1). }\end{array}$ & $\begin{array}{l}\text { No se contempla } \\
\text { expresamente la } \\
\text { posibilidad de } \\
\text { implantar canales } \\
\text { anónimos. }\end{array}$ \\
\hline
\end{tabular}

102 Sin embargo, en el informe del gobierno que acompaña la propuesta se muestra una posición reticente respecto de este tipo de denuncias. En concreto, se dice que "Los informes anónimos pueden ayudar a abordar infracciones o infracciones. Sin embargo, también existen desventajas para la detección, la imposición de sanciones y la protección de las personas afectadas que son sometidas a la legislación nacional en relación con la infracción del Derecho de la Unión o el abuso. En opinión del gobierno, una obligación general de verificar informes anónimos enfrenta demasiados problemas previsibles, pero también imprevisibles. Por ejemplo, después de una denuncia anónima, no se puede llevar a cabo ninguna investigación basada en un procedimiento contradictorio y es difícil proteger a un denunciante anónimo contra desventajas. Por lo tanto, el gobierno opina que tal deber debe ser considerado a la luz de todas las circunstancias que surgen en ese campo y de las tareas y poderes de las autoridades competentes" (traducción no oficial). Disponible en: https://www.tweedekamer.nl/downloads/ 


\begin{tabular}{|c|c|c|c|}
\hline & Holanda ${ }^{99}$ & Portugal $^{100}$ & Suecia $^{101}$ \\
\hline $\begin{array}{l}\text { Autoridades } \\
\text { competentes } \\
\text { encargadas } \\
\text { de los canales } \\
\text { externos }\end{array}$ & $\begin{array}{l}\text { La autoridad designada } \\
\text { con carácter general } \\
\text { es un organismo } \\
\text { autónomo creado a } \\
\text { tal efecto: Huis voor } \\
\text { Klokkenluiders (la casa } \\
\text { de los denunciantes) }{ }^{103} \text {. } \\
\text { No obstante, también } \\
\text { se designan a otras } \\
\text { autoridades para que } \\
\text { en el ámbito de sus } \\
\text { funciones lleven a } \\
\text { cabo esta tarea (ej. la } \\
\text { autoridad holandesa en } \\
\text { materia de consumo). }\end{array}$ & $\begin{array}{l}\text { Se designa a las } \\
\text { autoridades que, } \\
\text { de acuerdo con sus } \\
\text { competencias, deban o } \\
\text { puedan verse afectados } \\
\text { por el asunto objeto de } \\
\text { la denuncia, haciendo } \\
\text { referencia expresa } \\
\text { a: Ministério Público, } \\
\text { os órgãos de polícia } \\
\text { criminal, as entidades } \\
\text { administrativas } \\
\text { independentes, Os } \\
\text { institutos públicos, } \\
\text { As inspeções-gerais e } \\
\text { entidades equiparadas e } \\
\text { outros serviços centrais } \\
\text { da administração } \\
\text { direta do Estado } \\
\text { dotados de autonomia } \\
\text { administrativa, As } \\
\text { autarquias locais, as } \\
\text { associações públicas } \\
\text { (art. 12.1). }\end{array}$ & $\begin{array}{l}\text { la propuesta de ley. } \\
\text { En todo momento se } \\
\text { refiere a la "autoridad } \\
\text { que el gobierno } \\
\text { designe como } \\
\text { autoridad competente } \\
\text { dentro de un área } \\
\text { determinada" (cap. 6). }\end{array}$ \\
\hline
\end{tabular}

document?id=aa664827-d3f3-4c9f-a618-eadae2f68bcf\&title=Memorie\%20 van\%20toelichting.pdf>. Acceso en: 14 ago. 2021.

${ }^{103}$ Más información sobre este organismo en: https://www.huisvoorklokkenluiders.nl/. Acceso en: 14 de ago. 2021. 


\begin{tabular}{|c|c|c|c|}
\hline & Holanda ${ }^{99}$ & Portugal $^{100}$ & Suecia $^{101}$ \\
\hline Sanciones & $\begin{array}{l}\text { El ordenamiento } \\
\text { holandés ya prevé } \\
\text { sanciones penales } \\
\text { y civiles para los } \\
\text { informantes que } \\
\text { intencionalmente } \\
\text { brinden información } \\
\text { incorrecta y para } \\
\text { las personas físicas } \\
\text { o jurídicas que } \\
\text { desalienten o } \\
\text { perjudiquen a los } \\
\text { informantes }^{104} \text {. }\end{array}$ & $\begin{array}{l}\text { En el art. } 26 \text { establece } \\
\text { un amplio catálogo } \\
\text { de sanciones } \\
\text { administrativas, } \\
\text { sin perjuicio } \\
\text { de las posibles } \\
\text { responsabilidades } \\
\text { penales. }\end{array}$ & $\begin{array}{l}\text { El proyecto de ley no } \\
\text { incorpora sanciones } \\
\text { específicas. }\end{array}$ \\
\hline
\end{tabular}

TABLA 2

\section{Consideraciones finAles}

La Directiva "Whistleblowing" va a suponer un punto de inflexión en las políticas anticorrupción dirigidas a proteger a los alertadores en Europa. Aunque su contenido no es muy ambicioso, ya que se limita a establecer un marco mínimo común para los Estados de la Unión Europea, tras realizar el análisis comparativo creemos que los Estados miembros, en sus respectivos procesos de transposición, van a optar mayoritariamente por extender la protección a los alertadores que reporten infracciones de normas que no tengan su origen en la Unión Europea.

Como hemos analizado en este trabajo a raíz de la consulta pública sobre la transposición de la Directiva planteada por el Ministerio de Justicia el 7 de enero de 2021, esta es la opción que parece que tiene más visos de prosperar en España. En caso de que así sea, será interesante comprobar

${ }^{104}$ Una exposición de las sanciones previstas en el ordenamiento holandés puede verse en el apartado 5 del informe. Disponible en: <https://www.tweedekamer.nl/downloads/document?id=aa664827-d3f3-4c9f-a618-eadae2f68bcf\&title=Memorie\%20van\%20toelichting.pdf $>$. Acceso en: 14 ago. 2021. 
si esa expansión del ámbito material tiene carácter indiscriminado o si se extiende únicamente a algunos sectores de nuestro ordenamiento en los que se considere que concurren razones de interés general.

Al hilo de esta idea, creemos que el legislador español debe aprovechar la transposición de la Directiva para diseñar un régimen jurídico común y transversal que garantice la protección de los alertadores, sin perjuicio de las reglas sectoriales que se puedan aprobar en esta materia. Más allá de las concretas medidas que se quieran adoptar, a nuestro juicio, el régimen jurídico que resulte de este proceso debe brindar la seguridad jurídica que los ciudadanos precisan. Para ello, entendemos que la mejor opción es la de aprobar una ley general que evite la dispersión normativa y ponga coto a la proliferación de normativas autonómicas sobre la materia.

Por otro lado, tendremos que estar atentos para ver qué sucede finalmente con dos de los temas más problemáticos: la admisión de denuncias anónimas y la concesión de premios o recompensas a los alertadores ${ }^{105}$. Es evidente que, en términos de eficacia, sería recomendable dar validez a las denuncias anónimas y, en su caso, premiar a aquellos alertadores que hayan reportado determinadas infracciones. Sin embargo, nos parece que este tipo de medidas podría traer más perjuicios que beneficios. La admisión de las denuncias anónimas, como hemos comentado, podría favorecer el uso fraudulento de los canales de denuncias y fomentar un ambiente de desconfianza mutua en las organizaciones. Asimismo, la concesión de premios y recompensa a los alertadores nos parecería una medida muy poco acertada. Entre otras cosas porque con ella se correría el riesgo de convertir a los alertadores en una suerte de "cazarecompensas" en lugar de ciudadanos que cumplen con un deber ético. Algo que, como es lógico, no ayudaría a mejorar su imagen ante la sociedad. A nuestro juicio, a la hora de abordar todas estas cuestiones, el legislador español no debe perder de vista que en esta materia no solo está en juego la protección de los alertadores y la eficacia de los canales de denuncias para detectar irregularidades, sino también los derechos fundamentales de las personas denunciadas. Desde esta perspectiva, esperamos que nuestro legislador

${ }^{105}$ Ampliamente sobre esta cuestión vid. ORTIZ PRADILLO, J. C. Los delatores en el proceso penal: recompensas, anonimato, protección y otras medidas para incentivas una colaboración eficaz con la Justicia. Madrid: Wolters Kluwer, 2018. 
pondere adecuadamente los bienes jurídicos en conflicto para que la exigencia de eficacia en la detección e investigación de infracciones no suponga una merma de los derechos y garantías de los ciudadanos.

Por último, al hilo de esta idea queremos resaltar que, desde nuestro punto de vista, para que la Directiva cumpla con sus objetivos no solo será necesario que los Estados miembros estén acertados en su transposición, sino que será imprescindible también una labor de difusión y de concienciación de la ciudadanía, especialmente en aquellos países en los que la labor de los alertadores sigue estando estigmatizada-como es el caso de España-. De lo contrario, por más que el ordenamiento jurídico obligue a las entidades jurídicas a implantar canales internos de denuncia y refuerce la protección de los alertadores, será difícil que este instrumento pueda desarrollar todo su potencial.

\section{Referencias}

ABAZI, Vigjilenca. The European Union Whistleblower Directive: A'Game Changer' for Whistleblowing Protection. Industrial Law Journal, vol. 49, Issue 4, 2020. https://doi.org/10.1093/indlaw/dwaa023

AMERIGO ALONSO, José. Los retos de la transposición de la Directiva Whistleblowing. Diario La Ley, Madrid, n. 9699, 2020.

ANN JOHNSON, Roberta. Whistleblowing: When it Works-and Why. Boulder: Lynne Rienner, 2003.

ARMENTA DEU, Teresa. Derivas de la justicia: tutela de los derechos y solución de controversias en tiempos de cambios. Madrid: Marcial Pons, 2021.

BACHMAIER WINTER. Lorena, MARTÍNEZ SANTOS, Antonio. El régimen jurídico-procesal del whistleblower. La influencia del Derecho europeo. GÓMEZ COLOMER, Juan Luis, Tratado sobre compliance penal, Valencia: Tirant lo Blanch. 2019.

BACHMAIER WINTER. Lorena. Whistleblowing europeo y compliance: La Directiva EU de 2019 relativa a la protección de personas que reporten infracciones del Derecho de la Unión. Diario La Ley, Madrid, n. 9539, de 18 de diciembre de 2019. BUCY, Pamela. Information as a commodity in the regulatory world. Houston Law Review, Houston, vol. 39, issue 4, 2002.

CAMPANÓN GALIANA, Laura. Análisis de la Directiva (UE) 2019/1937 del Parlamento Europeo y del Consejo de 23 de octubre de 2019 (Whistleblowing), 
relativa a la protección de las personas que informen sobre infracciones del Derecho de la Unión. Carta Tributaria. Revista de Opinión, n. 59, 2020.

CEVA, Emanuela y BOCCHIOLA, Michele. Theories of whistleblowing. Philosophy Compass, 2019. https://doi.org/10.1111/phc3.12642

DE ZWART, Alja Poler. EU whistleblowing rules to change in favor of whistleblowers. Journal of investment compliance, vol. 21, n. 1, 2020. https://doi.org/10.1108/ joic-08-2020-0015

FERNÁNDEZ GONZÁLEZ, María Cristina. ¿Proteger o premiar al whistleblower?: Un debate pendiente en España, GONZÁLEZ GARCÍA, Nicolás y CARRIZO GONZÁLEZ-CASTELL, Adán. Corrupción: Compliance, Represión y Recuperación de Activos. Valencia: Tirant lo Blanch, 2019. https://doi.org/10.20318/ eunomia.2020.5735

GARCÍA-MORENO, Beatriz. El concepto de alertador (o whistleblower). En: RODRÍGUEZ-GARCÍA, Nicolás; RODRÍGUEZ-LÓPEZ, Fernando (edits.). Compliance y responsabilidade de las personas jurídicas, Tirant lo Blanch, Valencia, 2021.

GARCÍA MORENO, Beatriz. Del whistleblower al alertador. La regulación europea de los canales de denuncia. Valencia: Tirant lo Blanch, 2020.

GARRÓS FONT, Imma; ROMERA SANTIAGO, Nuria. Hacia una protección efectiva de los denunciantes. Actualidad Administrativa, Madrid, n. 7-8, julio-agosto 2020.

KAFTERANIS, Dimitrios. A new enforcement tool: a directive to protect whistle-blowers. Business Law Review, vol. 41, issue 2, 2020.

LOZANO CUTANDA, Blanca. La directiva de protección del denunciante. Diario La Ley, Madrid, n. 9550, 2020.

MAGRO SERVET, Vicente. ¿Por qué es recomendable un canal de denuncias interno en la empresa?, Diario La Ley, Madrid, n. 9586, de 4 de marzo de 2020.

MARTÍNEZ SALDAÑA, David; ABRIL MARTÍNEZ, Javier; RODRÍGUEZ CELADA, Enrique y REYES RICO, Laia. La protección del whistleblower tras la Directiva (UE) 2019/1937. Análisis del nuevo marco jurídico desde la perspectiva del Derecho Laboral, Público, Penal y de Protección de Datos. Actualidad jurídica Uría Menéndez, Madrid, n. ${ }^{\circ}$ 53-2019, 2019. https://doi.org/10.2307/j.ctv14t46sm.8

MECHTENBERG, Lydia; MUEHLHEUSSER, Gerd; ROIDER, Andreas. Whistleblower protection: Theory and experimental evidence. European Economic Review, n. 126, 2020.

MORALES MARTÍN, Tamara. Canal de denuncias interno (whistleblowing), ¿anónimos o no? Esa es la cuestión. Legal Today. 29 de agosto de 2018. Disponible en: <(https://www.legaltoday.com/opinion/blogs/nuevas-tecnologias-blogs/ 
blog-prodat/canal-de-denuncias-interno-whistleblowing-anonimos-o-no-esa-es-la-cuestion-2018-08-29/>. Acceso en: 2 mar 2021.; última consulta: 02/03/2021).

ORTIZ PRADILLO, Juan Carlos. La delación premiada en España: instrumentos para el fomento de la colaboración con la justicia. Revista Brasileira de Direito Processual Penal, Porto Alegre, vol. 3, n. 1, p. 43. https://doi.org/10.22197/rbdpp.v3i1.38

ORTIZ PRADILLO, Juan Carlos. Los delatores en el proceso penal: recompensas, anonimato, protección y otras medidas para incentivas una colaboración eficaz con la Justicia. Madrid: Wolters Kluwer, 2018.

PÉREZ TRIVIÑO, Jose Luis. Whistleblowing. Eunomía: Revista en Cultura de la Legalidad, n. 14, 2018. https://doi.org/10.20318/eunomia.2018.4170

PUYOL, Javier. El funcionamiento práctico del canal de compliance "whistleblowing”. Valencia: Tirant lo Blanch, 2017.

RAGUÉS I VALLÈS, Ramón. ¿Es necesario un estatuto para los denunciantes de la corrupción?. Diario La Ley, Madrid, n. 9003, 19 de Junio de 2017.

RAGUÉS I VALLÈS, Ramón. El tratamento jurídico de los denunciantes antes y después de la Directiva 2019/1937. La Ley Compliance Penal, Madrid, n.1, 2020.

RAGUÉS I VALLÈS, Ramón. ¿Héroes o traidores? La protección de los informantes internos (whistleblowers) como estrategia político-criminal. InDret, Barcelona, n. $3 / 2006$.

SÁEZ LARA, Carmen. La protección de denunciantes: propuesta de regulación para España tras la Directiva Whistleblowing. Valencia: Tirant lo Blanch, 2020.

STAPPERS, Jan Tadeusz. EU Whistleblower Protection Directive: Europe on Whistleblowing. ERA Forum: Journal of the Academy of European Law, 2021. https://doi.org/10.1007/s12027-021-00649-7

TORRENT I SANTAMARIA, Josep María y PÉREZ GIL DE GÓMEZ, Laura. Análisis de la Directiva Europea de whistleblowing y principales retos de la nueva regulación. El caso de España. Derecho PUCP, n. 85, 2020. https://doi.org/10.18800/ derechopucp.202002.003

VESTRI, Gabriele. Aproximación al sistema de “whistleblowing”. Un nuevo desafío para la Administración Pública española. Revista General de Derecho Administrativo, Madrid, n. 51, 2019.

ZUÑIGA RODRÍGUEZ, Laura. Corrupción y la categoría de "delito de cuello blanco": cuando los delitos se cometen en contextos normalizados. Revista IUS ET VERITAS, Lima, n. 57, 2018. https://doi.org/10.18800/iusetveritas.201802.009 


\section{Additional information and author's declarations (scientific integrity)}

Conflict of interest declaration: the author confirms that there are no conflicts of interest in conducting this research and writing this article.

Declaration of authorship: all and only researchers who comply the authorship requirements of this article are listed as authors; all coauthors are fully responsible for this work in its entirety.

Declaration of originality: the author assures that the text here published has not been previously published in any other resource and that future republication will only take place with the express indication of the reference of this original publication; he also attests that there is no third party plagiarism or self-plagiarism.

\section{Editorial process dates}

(http://www.ibraspp.com.br/revista/index.php/RBDPP/about/editorialPolicies)

- Submission: 13/04/2021

- Desk review and plagiarism check: 30/05/2021

- Review 1: 04/06/2021

- Review 2: 21/06/2021

- Preliminary editorial decision: 04/08/2021

- Correction round return 1: 14/08/2021

- Preliminary editorial decision 2: 31/08/2021

- Correction round return 2: 31/08/2021

- Final editorial decision: 02/09/2021

- Preprint deposit: 29/09/2021

- https://doi.org/10.1590/SciELOPreprints.2893

\section{Editorial team}

- Editor-in-chief: 1 (VGV)

- Assistant-editor: 1 (APGS)

- Reviewers: 2

\section{HOW TO CITE (ABNT BRAZIL):}

CARO CATALÁN, José. La Directiva "Whistleblowing": Aspectos clave de su transposición al ordenamiento jurídico español. Revista Brasileira de Direito Processual Penal, vol. 7, n. 3, p. 2155-2200, set./dez. 2021. https://doi.org/10.22197/rbdpp.v7i3.552

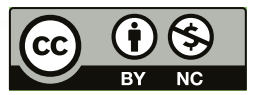

Esta obra está licenciada com uma Licença Creative Commons Atribuição-NãoComercial 4.0 Internacional. 